\title{
Ophiostomatoid fungi associated with Ips subelongatus, including eight new species from northeastern China
}

\author{
Zheng Wang ${ }^{1}$, Ya Liu' ${ }^{1}$, Huimin Wang ${ }^{1}$, Xianjing Meng ${ }^{1}$, Xuewei Liu ${ }^{1,2}$, Cony Decock ${ }^{3}$, Xingyao Zhang ${ }^{1}$ and
} Quan $\mathrm{Lu}^{1^{*}}$ (1)

\begin{abstract}
Ips subelongatus is a major pest that infects larch plantations over large areas of northern and northeastern China. Ips species are closely associated with ophiostomatoid fungi that are morphologically well-adapted for dispersal by beetles. These associations result in important threat for coniferous forests worldwide. The aim of this study was to characterize the ophiostomatoid communities associated with I. subelongatus infesting Larix species and sympatric Pinus sylvestris var. mongolica in northeastern China forests. Morphological and multilocus phylogenetic approaches (based on six markers: ITS, LSU, 60S, $\beta$-tubulin, EF-1a, and CAL gene regions) allowed identifying 14 species of four genera (Ceratocystiopsis, Endoconidiophora, Leptographium and Ophiostoma). Eight species are showed to be new to science. Most strains resided in two Ophiostoma species complexes, viz. the O. clavatum and the O. ips complexes, all together accounting for $76.8 \%$ of all isolates. Ophiostoma hongxingense sp. nov., O. peniculi sp. nov., and $O$. subelongati sp. nov. (O. clavatum complex) and O. pseudobicolor sp. nov. (O. ips complex) were the four dominant species. The ophiostomatoid communities associated with larch bark beetles, I. cembrae and I. subelongatus, in Europe and Asia, China and Japan, also were compared. These comparisons showed distinct, specific assemblage patterns.
\end{abstract}

Keywords: Ceratocystiopsis, Endoconidiophora, Leptographium, Ophiostoma, Taxonomy

\section{INTRODUCTION}

Globalization has hastened the emergence of tree pests, prompting the urgent need for a global strategy to manage the vitally important issues of forest pests (Wingfield et al. 2015). Bark beetles (Curculionidae: Scolytinae) are phloem-boring insects, some of which are the primary pests responsible for considerable mortality of coniferous forests in the northern hemisphere (Raffa et al. 2015). In Eurasia, species of the bark beetle genera Ips, Tomicus, and Dendroctonus have received a great deal of attention because of the damage they cause to local forest ecosystems and/or to tree plantations (Miao et al. 2001, Grégoire \& Evans 2004, Vega \& Hofstetter 2014).

\footnotetext{
* Correspondence: luquan@caf.ac.cn

${ }^{1}$ Key Laboratory of Forest Protection, National Forestry and Grassland Administration; Research Institute of Forest Ecology, Environment and Protection, Chinese Academy of Forestry, Beijing 100091, China Full list of author information is available at the end of the article
}

Ips subelongatus is a widely distributed bark beetle species in east Asia, spanning over Japan, Korea, Northern China, Mongolia, and the Russian Far East. It infests numerous Larix species (Pinaceae) including L. gmelinii, L. olgensis, L. principis-rupprechtii, L. kaempferi, L. sibirica, and sometimes Pinus spp. In China, I. subelongatus mainly infects three allopatric larches (Yang et al. 2007); they are L. gmelinii in the Da Xing'an and Xiao Xing'an mountain ranges in the Inner Mongolia Autonomous Region and Heilongjiang Province, L. olgensis in southeastern Heilongjiang Province, the Chang Bai mountain range in Jilin and Liaoning Provinces, and L. principisrupprechtii in middle Inner Mongolia as well as Beijing, Hebei, and Shanxi Provinces. These larches constitute the main component of one of the largest forested area in northeastern China.

The Asian eight spined larch bark beetle has commonly been considered a secondary pest that mainly attacks dying trees or colonizes stock logs (Stauffer et al. 
2001, Yamaoka et al. 1998). However, extensive infestations of larches with high insect density, high tree mortality rates, and subsequent forest decline have been noticed in these areas since the 1980s (Yin et al. 1984, Yu 1992, Zhang et al. 2007). Because of possible incidental introductions through the timber trade, I. subelongatus was presented in the EPPO alert list $\mathrm{A} 2$ as an important pest that is affecting coniferous trees in native regions and which represents a threat to non-native regions (EPPO 2005).

The association between beetles and fungi commonly plays an important role in the success of beetle colonization (Kirisits 2004). One of the most important beetle associated fungal groups are the ophiostomatoid fungi (Wingfield et al. 1993, Kirisits 2004). Ophiostomatoid fungi are an assemblage of species that share similar morphological and ecological traits. They belong mainly to the order Ophiostomatales (Sordariomycetidae, Sordariomycetes, Ascomycota), which includes the genera Ophiostoma, Leptographium, Sporothrix, Raffaelea, and Ceratocystiopsis, and to the order Microascales (Hypocreomycetidae, Sordariomycetes, Ascomycota), which includes Ceratocystis, Graphium and Endoconidiophora (De Beer \& Wingfield 2013, De Beer et al. 2014, De Beer et al. 2016). These fungi are assumed to be closely associated with bark beetles because of their morphological and ecological characteristics (Kirisits 2004). Some of these fungi are known as trees pathogens [e.g. Ophiostoma ulmi and O. novo-ulmi causing the Dutch elm disease (De Hoog et al. 1974, Brasier 1991), Leptographium wageneri, responsible for the black root disease (Harrington \& Cobb 1988), or Endoconidiophora fujiensis, which could kill mature larch trees (Yamaoka et al. 1998)], but the majority are blue stain agents of timber, causing economic and ecological losses to the forestry industry.

The ophiostomatoid fungi associated with I. subelongatus in Japan have been investigated systematically by Aoshima (1965), Westhuizen et al. (1995), Yamaoka et al. (1998, Yamaoka et al. 2009), Chung et al. (2006), Masuya et al. (2009) and Ando et al. (2016). Yamaoka (2017) has summarized the taxonomic knowledge of these fungi in Japan, where at least 12 species were reported to be associated with $I$. subelongatus, including five species of Ophiostoma, three of Grosmannia, two of Endoconidiophora, and one of Ceratocystiopsis and Graphilbum (Additional file 1: Table S1).

The association of ophiostomatoid fungi with I. subelongatus has been reported sporadically in China. So far, ten species have been recorded in northeastern China, viz. Endoconidiophora fujiensis, Graphium laricis, Gr. carbonarium, Leptographium altius, L. innermongolicum, L. manifestum, L. taigense, L. zhangii, Ophiostoma piceae and O. olgensis (Paciura et al. 2010a, b; Meng et al. 2015; Liu et al. 2016, 2017; Wang et al. 2016; see Additional file 1: Table S1). However, a comprehensive study of their diversity, distribution and host ranges, and ecological role is still lacking.

The primary goal of the present study is to fill this gap in the knowledge of the communities of ophiostomatoid fungi on larch species in northeastern China, based on an extensive field survey and using integrated morphological observations and multilocus DNA sequence data to characterize the species. The occurrences of the ophiostomatoid communities in larch forests are analyzed. In addition to species diversity, communities among European and Asian eight spined larch bark beetles are also compared.

\section{MATERIALS AND METHODS}

\section{Collection of samples and isolation of fungi}

Fungi were isolated from adults of Ips subelongatus and their breeding galleries in Larix gmelinii, L. olgensis, L. principis-rupprechtii and, in some cases, in Pinus sylvestris var. mongolica during the beetle's second mass flight period, which is from July to August, at 20 locations in northeastern China, including the three provinces of Heilongjiang, Liaoning, and Jilin and the autonomous region of Inner Mongolia (Fig. 1), from year 2010 to 2017. At each sampling location, beetle infested bark areas were collected from three to five dying trees or stock logs. Adults of I. subelongatus and their galleries were placed individually in sterile Eppendorf tubes and envelope bags, respectively. These organisms were subsequently stored at $4{ }^{\circ} \mathrm{C}$ until fungal isolation. Ten later-developed galleries in phloem and 10 adult beetles collected from these galleries at each location were used for fungal isolation. Galleries were disinfected for $1 \mathrm{~min}$ with $1.5 \%$ sodium hypochlorite, rinsed with sterile water three times, then cut into tissue pieces approximately $3 \times 3 \mathrm{~mm}^{2}$ in a laminar flow hood, and five pieces of each gallery were selected and transferred onto $2 \%$ malt extract agar (MEA, malt extract and agar: AoBoXing Company Ltd., Beijing, China; recipe: add $20 \mathrm{~g}$ malt extract and $20 \mathrm{~g}$ agar per $1000 \mathrm{~mL}$ water). Adult beetles were crushed on the surface of $2 \%$ MEA without superficial disinfection. After a period of incubation at $25^{\circ} \mathrm{C}$ in dark, all strains were purified by single-spore isolations and/or mycelium apex and routinely grown on 2\% MEA. After an initial analysis of macro- and microscopical characteristics, representative strains of each morphotype were selected for further in-depth morphological, physiological, and molecular studies. All strains were deposited in the culture collection of the Chinese Academy of Forestry (CXY) (Table 1). Representatives were also deposited 

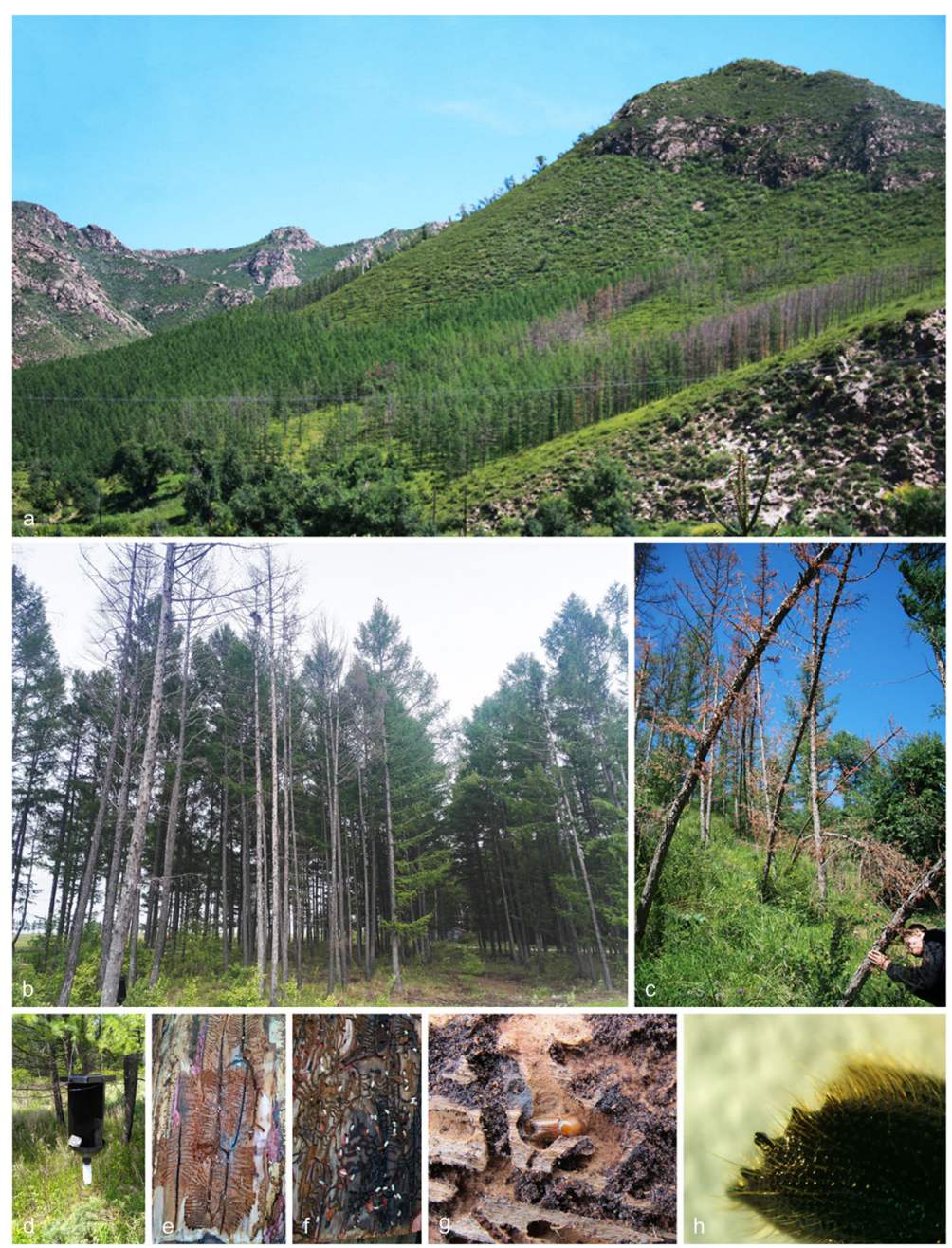

Fig. 1 a-c. Disease symptoms on larch infested by Ips subelongatus and ophiostomatoid fungi in northeastern China; d. Cross barrier type traps used in fields for monitoring the occurrence and population of I. subelongatus; $\mathbf{e - g}$. Larvae, pupae, and adult of I. subelongatus in galleries on larch; h. Spines of I. subelongatus

at the China Forestry Culture Collection Centre (CFCC) and the Mycothèque of the Université Catholique de Louvain, Belgium (BCCM/MUCL) (Table 1).

\section{Morphological and cultural studies}

Morphological structures were observed and recorded using an Olympus BX51 microscope, Olympus SZX16 stereomicroscope, and Olympus DP70 digital camera (Olympus, Centre Valley, PA, USA). For the strains selected as holotypes, the lengths and widths of 30 reproductive structures per strain were measured. The average (mean), standard deviation (SD), minimum $(\min )$, and maximum $(\max )$ measurements are presented as the (min-) (mean - SD) $-($ mean $+\mathrm{SD})(-\max )$.

For growth rate studies, a $5 \mathrm{~mm}$ diameter agar plug was taken from an actively growing fungal colonies and placed in the centre of $90 \mathrm{~mm}$ diameter Petri plates containing 2\% MEA. These cultures were then incubated in the dark at $5{ }^{\circ} \mathrm{C}$ intervals from 5 to $40{ }^{\circ} \mathrm{C}$. There were five replicate plates of each strain at each temperature, and two orthogonal diameter measurements were recorded daily until the fastest-growing mycelium reached the edge of the MEA plate. Colony colors were described based on the color chart of Rayner (1970). All relevant data pertaining to type specimens were deposited into MycoBank (http://www.MycoBank.org/).

DNA extraction, amplification, and nucleotide sequencing Prior to DNA extraction, the strains were grown on $2 \%$ MEA at $25^{\circ} \mathrm{C}$ for 5 to 7 days. The actively growing mycelium from one MEA plate per strain was scraped from the surface of the medium using a sterile scalpel and transferred to $1.5 \mu \mathrm{L}$ Eppendorf tubes. DNA extractions and purification were conducted using an Invisorb Spin 
Table 1 Strains of ophiostomatoid fungi sequenced and used for morphological and phylogenetic analysis in this study

\begin{tabular}{|c|c|c|c|c|c|c|c|c|}
\hline \multirow[t]{2}{*}{ Taxon } & \multirow[t]{2}{*}{ Species $^{1}$} & \multirow[t]{2}{*}{ Strain no. ${ }^{2.3 .4}$} & \multirow[t]{2}{*}{ Host } & \multirow[t]{2}{*}{ Locality } & \multicolumn{4}{|c|}{ GenBank number $^{5}$} \\
\hline & & & & & $\begin{array}{l}\text { ITS/LSU/ } \\
605\end{array}$ & $\beta T$ & EF-1a & CAL \\
\hline \multirow[t]{2}{*}{1} & $\begin{array}{l}\text { Ophiostoma } \\
\text { genhense }\end{array}$ & CFCC 52675 (CXY 2001) T & Larix gmelinii & $\begin{array}{l}\text { Genhe, Inner } \\
\text { Mongolia }\end{array}$ & MK748199 & MN896026 & MN896074 & MN896102 \\
\hline & & CFCC 52676 (CXY 2002) & L. gmelinii & $\begin{array}{l}\text { Genhe, Inner } \\
\text { Mongolia }\end{array}$ & N/A & MN896028 & MN896073 & MN896101 \\
\hline \multirow[t]{5}{*}{2} & O. hongxingense & CFCC 52695 (CXY 2021) T & L. gmelinii & Harbin, Heilongjiang & MK748194 & MN896027 & MN896068 & MN896089 \\
\hline & & CFCC 52696 (CXY 2022) & L. gmelinii & Harbin, Heilongjiang & N/A & MN896030 & MN896067 & MN896090 \\
\hline & & CXY 1905 & L. gmelinii & Harbin, Heilongjiang & N/A & MN896029 & MN896066 & MN896087 \\
\hline & & CXY 1906 & L. gmelinii & Harbin, Heilongjiang & N/A & MN896036 & MN896070 & MN896088 \\
\hline & & CXY 1907 & L. gmelinii & Harbin, Heilongjiang & $\mathrm{N} / \mathrm{A}$ & MN896037 & MN896069 & MN896091 \\
\hline \multirow[t]{2}{*}{3} & O. lotiforme & $\begin{array}{l}\text { CFCC } 52691 \\
(\text { CXY } 2017=\text { MUCL 55165) } T\end{array}$ & $\begin{array}{l}\text { Pinus sylvestris } \\
\text { var. mongolica }\end{array}$ & $\begin{array}{l}\text { Hailar, Inner } \\
\text { Mongolia }\end{array}$ & MK748185 & MN896044 & $\mathrm{N} / \mathrm{A}$ & N/A \\
\hline & & CFCC 52692 (CXY 2018) & $\begin{array}{l}\text { P. sylvestris var. } \\
\text { mongolica }\end{array}$ & $\begin{array}{l}\text { Hailar, Inner } \\
\text { Mongolia }\end{array}$ & MK748201 & MN896045 & N/A & N/A \\
\hline \multirow[t]{2}{*}{4} & O. minus & CFCC 52697 (CXY 2023) & L. gmelinii & $\begin{array}{l}\text { Arongqi, Inner } \\
\text { Mongolia }\end{array}$ & MK748202 & MN896050 & $\mathrm{N} / \mathrm{A}$ & N/A \\
\hline & & $\begin{array}{l}\text { CFCC } 52698 \\
(\text { CXY } 2024=\text { MUCL 55157) }\end{array}$ & $\begin{array}{l}\text { P. sylvestris } \\
\text { var. mongolica }\end{array}$ & $\begin{array}{l}\text { Hailar, Inner } \\
\text { Mongolia }\end{array}$ & MK748187 & MN896051 & $\mathrm{N} / \mathrm{A}$ & N/A \\
\hline \multirow[t]{2}{*}{5} & $\begin{array}{l}\text { O. } \\
\text { multisynnematum }\end{array}$ & CFCC 52677 (CXY 2003) T & L. gmelinii & $\begin{array}{l}\text { Genhe, Inner } \\
\text { Mongolia }\end{array}$ & MK748196 & MN896048 & MN896071 & MN896103 \\
\hline & & CFCC 52678 (CXY 2004) & L. gmelinii & $\begin{array}{l}\text { Genhe, Inner } \\
\text { Mongolia }\end{array}$ & N/A & MN896049 & MN896072 & MN896104 \\
\hline \multirow[t]{4}{*}{6} & O. olgensis & CFCC 52699 (CXY 2025) & L. gmelinii & $\begin{array}{l}\text { Genhe, Inner } \\
\text { Mongolia }\end{array}$ & MK748204 & MN896046 & $\mathrm{N} / \mathrm{A}$ & N/A \\
\hline & & CFCC 52700 (CXY 2026) & L. gmelinii & $\begin{array}{l}\text { Genhe, Inner } \\
\text { Mongolia }\end{array}$ & MK748195 & MN896047 & $\mathrm{N} / \mathrm{A}$ & N/A \\
\hline & & CXY 1908 & L. gmelinii & Harbin, Heilongjiang & MK748203 & MN896034 & $\mathrm{N} / \mathrm{A}$ & N/A \\
\hline & & CXY 1909 & L. gmelinii & $\begin{array}{l}\text { Yichun, } \\
\text { Heilongjiang }\end{array}$ & MK748205 & MN896033 & $\mathrm{N} / \mathrm{A}$ & N/A \\
\hline \multirow[t]{3}{*}{7} & O. peniculi & CFCC 52687 (CXY 2013) T & L. gmelinii & $\begin{array}{l}\text { Genhe, Inner } \\
\text { Mongolia }\end{array}$ & MK748198 & MN896035 & MN896063 & MN896086 \\
\hline & & CFCC 52688 (CXY 2014) & L. gmelinii & $\begin{array}{l}\text { Genhe, Inner } \\
\text { Mongolia }\end{array}$ & N/A & MN896038 & MN896061 & MN896084 \\
\hline & & CXY 1904 & L. gmelinii & $\begin{array}{l}\text { Genhe, Inner } \\
\text { Mongolia }\end{array}$ & N/A & MN896040 & MN896062 & MN896085 \\
\hline \multirow[t]{6}{*}{8} & O. pseudobicolor & CFCC 52683 (CXY 2009) T & L. gmelinii & $\begin{array}{l}\text { Genhe, Inner } \\
\text { Mongolia }\end{array}$ & MK748188 & MN896043 & N/A & N/A \\
\hline & & CFCC 52684 (CXY 2010) & L. gmelinii & $\begin{array}{l}\text { Genhe, Inner } \\
\text { Mongolia }\end{array}$ & MK748190 & MN896041 & $\mathrm{N} / \mathrm{A}$ & N/A \\
\hline & & $\begin{array}{l}\text { CFCC } 52685 \\
(\text { CXY } 2011=\text { MUCL 55168) }\end{array}$ & $\begin{array}{l}\text { L. principis- } \\
\text { rupprechtii }\end{array}$ & $\begin{array}{l}\text { Chifeng, Inner } \\
\text { Mongolia }\end{array}$ & MK748191 & MN896039 & $\mathrm{N} / \mathrm{A}$ & N/A \\
\hline & & $\begin{array}{l}\text { CFCC } 52686 \\
(\text { CXY 2012 = MUCL 55174) }\end{array}$ & L. gmelinii & Mohe, Heilongjiang & MK748193 & MN896042 & $\mathrm{N} / \mathrm{A}$ & N/A \\
\hline & & CXY 1910 & $\begin{array}{l}\text { L. principis- } \\
\text { rupprechtii }\end{array}$ & $\begin{array}{l}\text { Chifeng, Inner } \\
\text { Mongolia }\end{array}$ & MK748192 & MN896058 & N/A & N/A \\
\hline & & CXY 1911 (MUCL 55170) & L. gmelinii & Tahe, Heilongjiang & MK748189 & MN896057 & $\mathrm{N} / \mathrm{A}$ & N/A \\
\hline \multirow[t]{2}{*}{9} & O. rufum & CFCC 52681 (CXY 2007) & L. gmelinii & $\begin{array}{l}\text { Genhe, Inner } \\
\text { Mongolia }\end{array}$ & MK748197 & MN896031 & MN896075 & MN896095 \\
\hline & & CFCC 52682 (CXY 2008) & L. gmelinii & $\begin{array}{l}\text { Genhe, Inner } \\
\text { Mongolia }\end{array}$ & N/A & MN896032 & MN896076 & MN896098 \\
\hline 10 & O. subelongati & CFCC 52693 (CXY 2019) T & L. gmelinii & Harbin, Heilongjiang & MK748200 & MN896055 & MN896064 & MN896092 \\
\hline
\end{tabular}


Table 1 Strains of ophiostomatoid fungi sequenced and used for morphological and phylogenetic analysis in this study (Continued)

\begin{tabular}{|c|c|c|c|c|c|c|c|c|}
\hline \multirow[t]{2}{*}{ Taxon } & \multirow[t]{2}{*}{ Species $^{1}$} & \multirow[t]{2}{*}{ Strain no. ${ }^{2.3 .4}$} & \multirow[t]{2}{*}{ Host } & \multirow[t]{2}{*}{ Locality } & \multicolumn{4}{|c|}{ GenBank number ${ }^{5}$} \\
\hline & & & & & $\begin{array}{l}\text { ITS/LSU/ } \\
605\end{array}$ & $\beta T$ & EF-1a & CAL \\
\hline & & CFCC 52694 (CXY 2020) & L. gmelinii & Harbin, Heilongjiang & N/A & MN896054 & MN896065 & MN896093 \\
\hline \multirow[t]{5}{*}{11} & O. xinganense & CFCC 52679 (CXY 2005) T & L. gmelinii & $\begin{array}{l}\text { Genhe, Inner } \\
\text { Mongolia }\end{array}$ & MK748186 & MN896056 & MN896078 & MN896097 \\
\hline & & CFCC 52680 (CXY 2006) & L. gmelinii & $\begin{array}{l}\text { Genhe, Inner } \\
\text { Mongolia }\end{array}$ & N/A & MN896059 & MN896079 & MN896094 \\
\hline & & CXY 1901 & L. gmelinii & $\begin{array}{l}\text { Genhe, Inner } \\
\text { Mongolia }\end{array}$ & N/A & MN896060 & MN896077 & MN896096 \\
\hline & & CXY 1902 & L. gmelinii & $\begin{array}{l}\text { Genhe, Inner } \\
\text { Mongolia }\end{array}$ & N/A & MN896026 & MN896080 & MN896099 \\
\hline & & CXY 1903 & L. gmelinii & $\begin{array}{l}\text { Genhe, Inner } \\
\text { Mongolia }\end{array}$ & N/A & MN896028 & MN896081 & MN896100 \\
\hline \multirow[t]{2}{*}{12} & $\begin{array}{l}\text { Ceratocystiopsis cf. } \\
\text { pallidobrunnea }\end{array}$ & CFCC 52689 (CXY 2015) & $\begin{array}{l}\text { P. sylvestris var. } \\
\text { mongolica }\end{array}$ & $\begin{array}{l}\text { Hailar, Inner } \\
\text { Mongolia }\end{array}$ & MN892641 & N/A & N/A & N/A \\
\hline & & CFCC 52690 (CXY 2016) & $\begin{array}{l}\text { P. sylvestris var. } \\
\text { mongolica }\end{array}$ & $\begin{array}{l}\text { Hailar, Inner } \\
\text { Mongolia }\end{array}$ & MN892642 & N/A & N/A & N/A \\
\hline \multirow[t]{2}{*}{13} & $\begin{array}{l}\text { Leptographium } \\
\text { zhangii }\end{array}$ & CFCC 52701 (CXY 2027) & L. gmelinii & $\begin{array}{l}\text { Genhe, Inner } \\
\text { Mongolia }\end{array}$ & N/A & N/A & MN896082 & N/A \\
\hline & & CFCC 52702 (CXY 2028) & L. gmelinii & $\begin{array}{l}\text { Genhe, Inner } \\
\text { Mongolia }\end{array}$ & N/A & N/A & MN896083 & N/A \\
\hline \multirow[t]{2}{*}{14} & $\begin{array}{l}\text { Endoconidiophora } \\
\text { fujiensis }\end{array}$ & CXY 1912 & L. gmelinii & $\begin{array}{l}\text { Yichun, } \\
\text { Heilongjiang }\end{array}$ & MN896105 & N/A & N/A & N/A \\
\hline & & CXY 1913 & L. gmelinii & $\begin{array}{l}\text { Yichun, } \\
\text { Heilongjiang }\end{array}$ & MN896106 & N/A & N/A & N/A \\
\hline
\end{tabular}

1. Species named in black bold are novel species in this study

2. CFCC China Forestry Culture Collection Center, Beijing, China

3. $C X Y$ the culture collection of the Chinese Academy of Forestry

4. $T=$ ex-holotype isolates

5. ITS Internal transcribed spacer regions 1 and 2 of the nuclear ribosomal DNA operon, including the 5.8S region, LSU Large subunit of the nrDNA, 60S partial 605 ribosomal protein RPL10 gene, $\beta T$ the $\beta$-tubulin gene region, EF-1a the transcription elongation factor-1a gene region, $C A L$ the calmodulin gene region

Plant Mini Kit (Tiangen, Beijing, China) following the manufacturer's instructions. The primer pairs ITS1/ITS4 (White et al. 1990), LROR/LR5 (Vilgalys \& Hester 1990), Algr52_412-433_f1/Algr52_1102_1084_r1 (Stielow et al. 2015), Bt2a/Bt2b (Glass \& Donaldson 1995), EF1F/EF2R (Jacobs et al. 2004) or EF2F (Marincowitz et al. 2015)/ EF2R, and CL2F/CL2R (Duong et al. 2012) or CL3F/ CL3R (Musvuugwa et al. 2015) were used for amplification of internal transcribed spacer regions 1 and 2 of the nuclear ribosomal DNA operon, including the $5.8 \mathrm{~S}$ region (ITS), the nuclear ribosomal large subunit region (LSU), the partial 60S ribosomal protein RPL10 gene $(60 S)$, the $\beta$-tubulin gene region $(\beta \mathrm{T})$, the transcription elongation factor- $1 \alpha$ gene region (EF-1 $\alpha$ ), and the calmodulin gene region (CAL), respectively.

The PCR assays were performed in $25 \mu \mathrm{L}$ volumes (2.5 mM $\mathrm{MgCl}_{2}, 1 \times$ PCR buffer, $0.2 \mathrm{mM} \mathrm{dNTP,} 0.2$ $\mathrm{mM}$ of each primer, and $2.5 \mathrm{U}$ Taq polymerase enzyme). The PCR conditions for amplification of the ITS region were an initial denaturation step at $94{ }^{\circ} \mathrm{C}$ for $3 \mathrm{~min}$, followed by 35 cycles of $1 \mathrm{~min}$ at $94{ }^{\circ} \mathrm{C}, 45 \mathrm{~s}$ at $55^{\circ} \mathrm{C}$, and $1 \mathrm{~min}$ at $72^{\circ} \mathrm{C}$, and then final chain elongation at $72{ }^{\circ} \mathrm{C}$ for $8 \mathrm{~min}$. The five other gene regions were amplified using a denaturation step at $95^{\circ} \mathrm{C}$ followed by 35 cycles under the same conditions as above, except that the annealing temperatures varied between 54 and $58{ }^{\circ} \mathrm{C}$ depending on the primers used, and a final chain elongation at $72{ }^{\circ} \mathrm{C}$ for $8 \mathrm{~min}$. The PCR products were cleaned using a MSB Spin PCRapace Kit (250) (Invitek, Berlin, Germany) according to the manufacturer's instructions.

Sequencing reactions were performed using a CEQ DTCS Quick Start Kit (Beckman Coulter, Brea, CA, USA) according to the manufacturer's instructions with the same PCR primers as above. Nucleotide sequences were determined using a CEQ $2000 \mathrm{XL}$ capillary automated sequencer (Beckman Coulter).

\section{Phylogenetic analysis}

Preliminary identifications of the strains were conducted using standard BLAST searches. Representative sequences with the highest similarity matching and type strain sequences of similar species were downloaded from GenBank. Alignments were constructed with the 
online tool MAFFT v.7 (Katoh \& Standley, 2013). The genus-level dataset was aligned using the FFT-NS-i strategy with a $200 \mathrm{PAM} / \mathrm{k}=2$ scoring matrix, a gap opening penalty of 1.53, and an offset value of 0.00 (Linnakoski et al. 2016). The species complex or group-level datasets consisted of closely-related DNA sequences and were thus aligned using the G-INS-i strategy with a 1 PAM/ $\mathrm{k}=2$ scoring matrix, a gap opening penalty of 1.53 , and an offset value of 0.00 (Linnakoski et al. 2016). Datasets were compiled in Molecular Evolutionary Genetic Analyses (MEGA) 7.0 (Kumar et al. 2016). Phylogenetic analyses of the aligned sequences were conducted using the maximum parsimony (MP), maximum likelihood (ML), and Bayesian inference (BI) methods.

PAUP* version 4.0b10 (Swofford 2003) was used for MP analysis, with gaps treated as a fifth base. One thousand bootstrap replicates were generated to estimate the branch node confidence, with max trees set to 200 and clades compatible with the $50 \%$ majority rule in the bootstrap consensus tree were retained. The analysis settings were as follows: tree bisection reconnection branch swapping, starting tree obtained via stepwise addition, steepest descent not in effect, and MulTrees effective.

ML phylogenetic analyses were conducted using RAxML-HPC v.8.2.3 (Stamatakis 2014) available in the CIPRES Science Gateway (Miller et al. 2010, http://www. phylo.org/); the GTR + G model of site substitution included estimation of Gamma-distributed rate heterogeneity and a proportion of invariant sites (Stamatakis 2006). ML bootstrap support values were estimated using 1000 bootstrap replicates.

For Bayesian analyses, the best substitution models for each data set were determined using the corrected Akaike Information Criterion (AICc) in jModelTest v. 2.1.7 (Darriba et al. 2012). Bayesian inferences using four Markov Chain Monte Carlo (MCMC) chains were run simultaneously in MrBayes v. 3.1.2 (Ronquist \& Huelsenbeck 2003) from a random starting tree for 5,000,000 generations to calculate posterior probabilities. Trees were sampled every 100 generations, and the first $25 \%$ of trees sampled were discarded as burn-in, while the remaining trees were used to calculate Bayesian posterior probabilities of the clades. Phylogenetic trees were edited in FigTree v. 1.4.3 (http://tree.bio.ed.ac.uk/software/figtree/) and Adobe Illustrator CS6. The final alignments and the retrieved topologies were deposited in TreeBASE (No. 24283).

\section{RESULTS}

\section{Collection of samples and isolation of fungi}

In total, 496 strains of ophiostomatoid fungi were obtained from the adult beetles and galleries. Growth rates, macro- and microscopical morphological features were used for preliminary identification. Standard nucleotide
BLAST searches at GenBank were performed using the BT sequences of all strains for preliminary sorting and searching for affinities. Subsequently, 41 representative strains were selected for in depth morphological study and multi-locus phylogenetic analysis (Table 1).

\section{Phylogenetic analysis}

The three phylogenetic methods used resulted in similar topologies with slight variations of the statistical support for each of the individual sequence datasets. Phylograms obtained by $\mathrm{ML}$ are presented for all the individual datasets, with branch supports obtained from ML, MP, and BI analyses indicated. The best-fit evolutionary models selected by jModelTest v. 2.1.7 were GTR + G [for the CAL dataset of $O$. piceae complex, the combined datasets $(\beta \mathrm{T}+\mathrm{CAL}+\mathrm{EF}-1 \alpha)$ of $O$. piceae and O. clavatum complexes, the EF- $1 \alpha$ datasets of O. piceae and O. clavatum complexes, the ITS dataset of $O$. ips complex], GTR + I (for the ITS datasets of O. minus complex and Group A, the EF-1 $\alpha$ dataset of Leptographium, the LSU dataset of Ceratocystiopsis), GTR + I+ G (for the ITS dataset of Ophiostoma), $\mathrm{HKY}+\mathrm{G}$ (for the $\beta \mathrm{T}$ datasets of $O$. piceae and $O$. minus complexes, the CAL dataset of $O$. clavatum complex), $\mathrm{HKY}+\mathrm{I}$ (for the $\beta \mathrm{T}$ datasets of $O$. clavatum and O. ips complexes, as well as Group A) and K80 (for the 60S dataset of Endoconidiophora).

The ITS sequences did not allow distinguishing closely related species in all cases but they enabled grouping strains into species complexes within Ophiostoma (Fig. 2). However, the partial DNA sequences of three protein-coding genes ( $\beta \mathrm{T}, \mathrm{CAL}, \mathrm{EF}-1 \alpha$, and combined) had sufficient internal information allowing identification of Ophiostoma to the species level (Figs. 3, 5, 6, 8, 10; Additional file 2: Figure S1, Additional file 3: Figure S2, Additional file 4: Figure S3, Additional file 5: Figure S4, Additional file 6: Figure S5, Additional file 7: Figure S6). The LSU, 60S, or EF DNA sequences also were employed to identify the strains of other three genera (Ceratocystiopsis, Endoconidiophora, and Leptographium) (Fig. 11; Additional file 8: Figure S7, Additional file 9: Figure S8).

The phylogenetic analyses showed that our 41 representative strains belonged to 14 terminal clades or phylogenetic species. Eleven phylogenetic species nested within the Ophiostoma lineage (Taxa 1-11), whereas the last three belonged to the Ceratocystiopsis (Taxon 12), Leptographium (Taxon 13), and Endoconidiophora lineages (Taxon 14).

\section{Ophiostoma s. I.}

Within Ophiostoma s.l., the ITS fragments were approximately 650 bp long. The ITS dataset included 88 entries representing 85 taxa and 663 positions (including gaps). Our strains nested in four species complexes in 


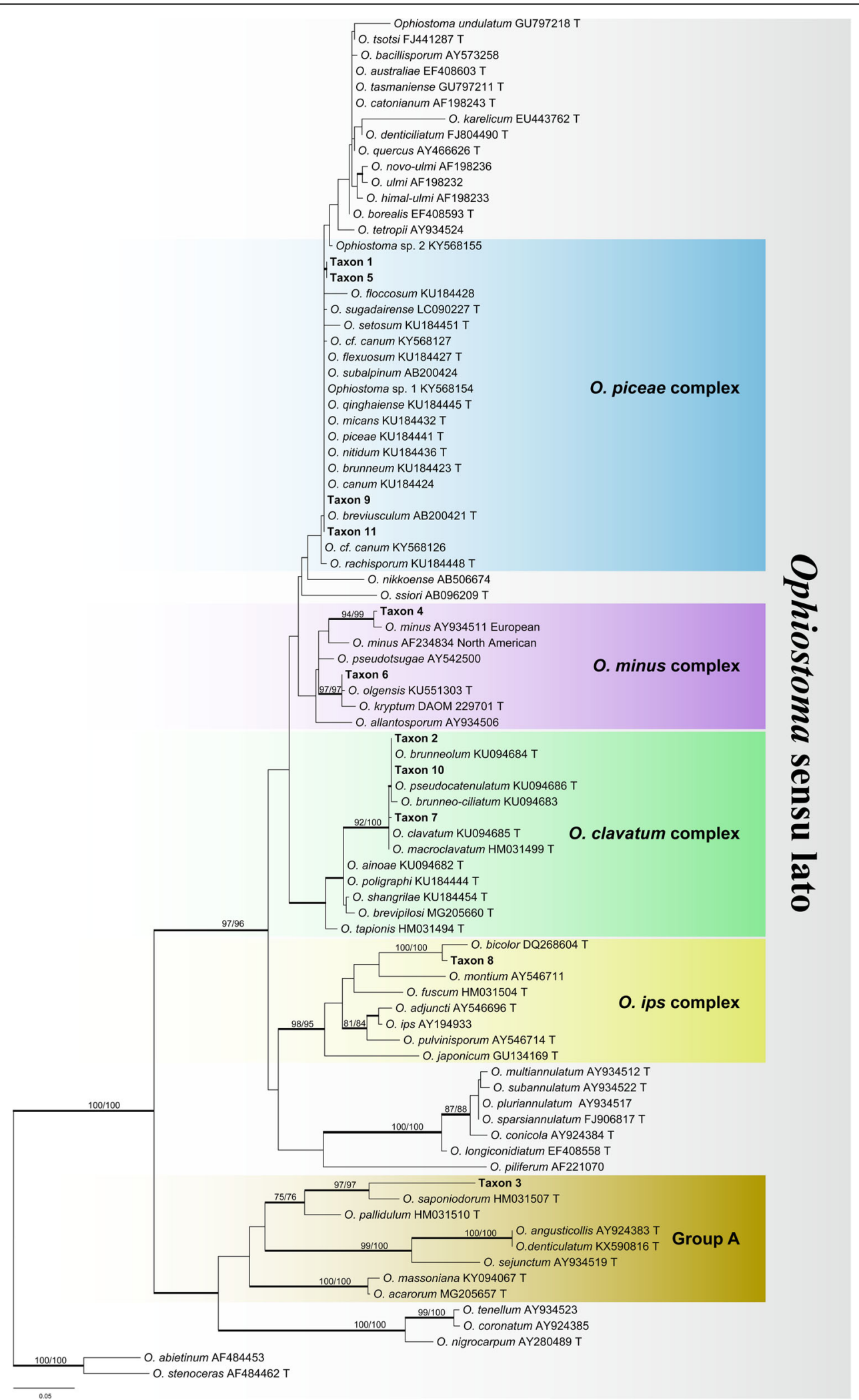

Fig. $2 \mathrm{ML}$ tree of Ophiostoma generated from the ITS sequence data. Sequences generated from this study are printed in bold. Bold branches indicate posterior probability values $\geq 0.9$. Bootstrap values of $\mathrm{ML} / \mathrm{MP} \geq 70 \%$ are recorded at the nodes. $T$ = ex-type isolates 


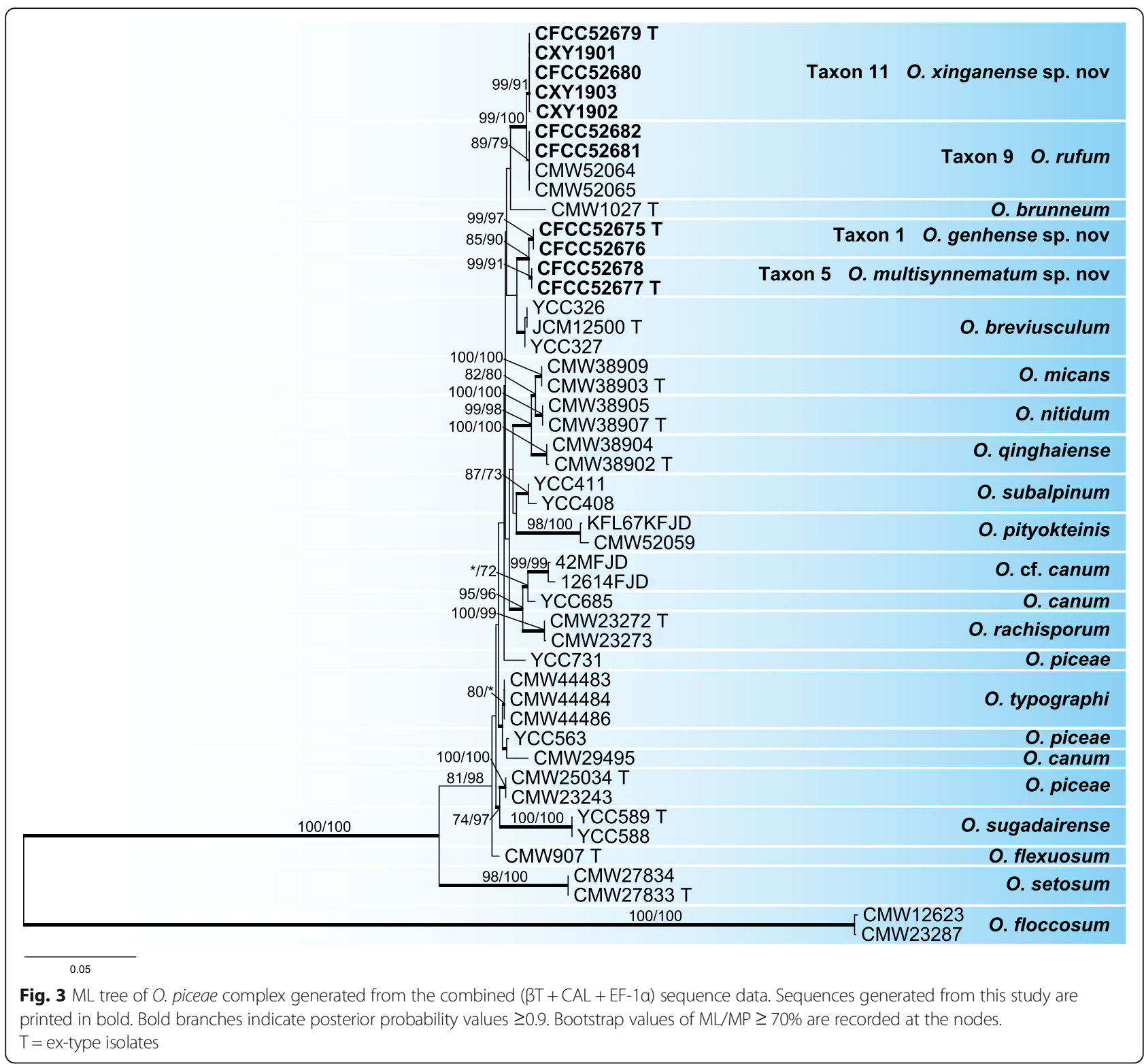

phylogenetic inferences, viz. the O. piceae complex (four representative strains), the $O$. minus complex (two representative strains), the $O$. clavatum complex (three representative strains), and the $O$. ips complex (one representative strain) (Fig. 2). Furthermore, one strains (representing one phylogenetic species) fall outside any currently recognized species complex but belong to the previously shown "Group A" (Chang et al. 2017).

Several DNA sequences subsets were compiled for identification of species level within species complexes. Three ITS subsets for the O. minus and O. ips complexes, and group A comprised respectively of 589,652 and 554 characters; five $\beta$ T subsets for the O. piceae, $O$. minus, $O$. clavatum, and $O$. ips complexes, as well as group A, contained 403, 442, 430, 441, and 565 characters, respectively; two EF- $1 \alpha$ subsets for the $O$. piceae and $O$. clavatum complexes, contained 1052 and 977 characters, respectively; two CAL subsets for the $O$. piceae and O. clavatum complexes, consisted of 961 and 931 characters, respectively. Two combined datasets $(\beta \mathrm{T}+\mathrm{CAL}+\mathrm{EF}-1 \alpha)$ for the O. piceae and O. clavatum complexes, consisted of 2418 and 2340 characters, respectively, including gaps.

Our 11 representative strains within the $O$. piceae complex formed four independent well-supported terminal clades representing four phylogenetic species (Taxa 1, 5, 9, and 11) in combined datasets $(\beta \mathrm{T}+\mathrm{CAL}+$ EF-1 $\alpha$ ) phylogenetic inferences (Fig. 3). These phylogenetic species were related to O. breviusculum, O. brunneum, and O. rufum (Jankowiak et al. 2019). Clades of 
taxa 1 and 5 are well-supported in phylogenetic analyses based on the $\beta \mathrm{T}, \mathrm{EF}-1 \alpha, \mathrm{CAL}$, and combined datasets (Additional file 2: Figure S1, Additional file 3: Figure S2, Additional file 4: Figure S3, Fig. 3). Clades of taxa 9 and 11 are shown in the EF- $1 \alpha$-based (Additional file 3: Figure S2) and combined datasets $(\beta T+C A L+E F-1 \alpha)$ for the $O$. piceae complex phylogenetic analyses (Fig. 3), whereas in phylogenetic inferences based on $\beta \mathrm{T}$ and CAL, these two clades collapsed (Additional file 2: Figure S1, Additional file 4: Figure S3).

Six representative strains of the $O$. minus complex were grouped into two independent well-supported clades of taxa 4 and 6 in the ITS based inferences (Fig. 4). The clade of taxon 4 was related to the $O$. minus Eurasian clade
(Gorton \& Webber 2000, Lu et al. 2009), and the clade of taxon 6 nested in the near vicinity of the O. olgensis and $O$. album clades. In the $\beta T$-based phylogram, the clade of taxon 4 separated into a well-supported subclade, which is a sister to a formerly defined Eurasian subclade within the O. minus clade (Fig. 5). Furthermore, the $\beta T$-based phylogram confirmed the strains of clade of taxon 6 represented O. olgensis (Fig. 5).

Ten representative strains belonging to the $O$. clavatum complex formed three independent terminal clades (Taxa 2,7 , and 10) with good support values in inferences based on the $\beta$ T (Additional file 5: Figure S4), EF- $1 \alpha$ (Additional file 6: Figure S5), CAL (Additional file 7: Figure S6), and combined dataset $(\beta T+C A L+E F-1 \alpha)($ Fig. 6). They were

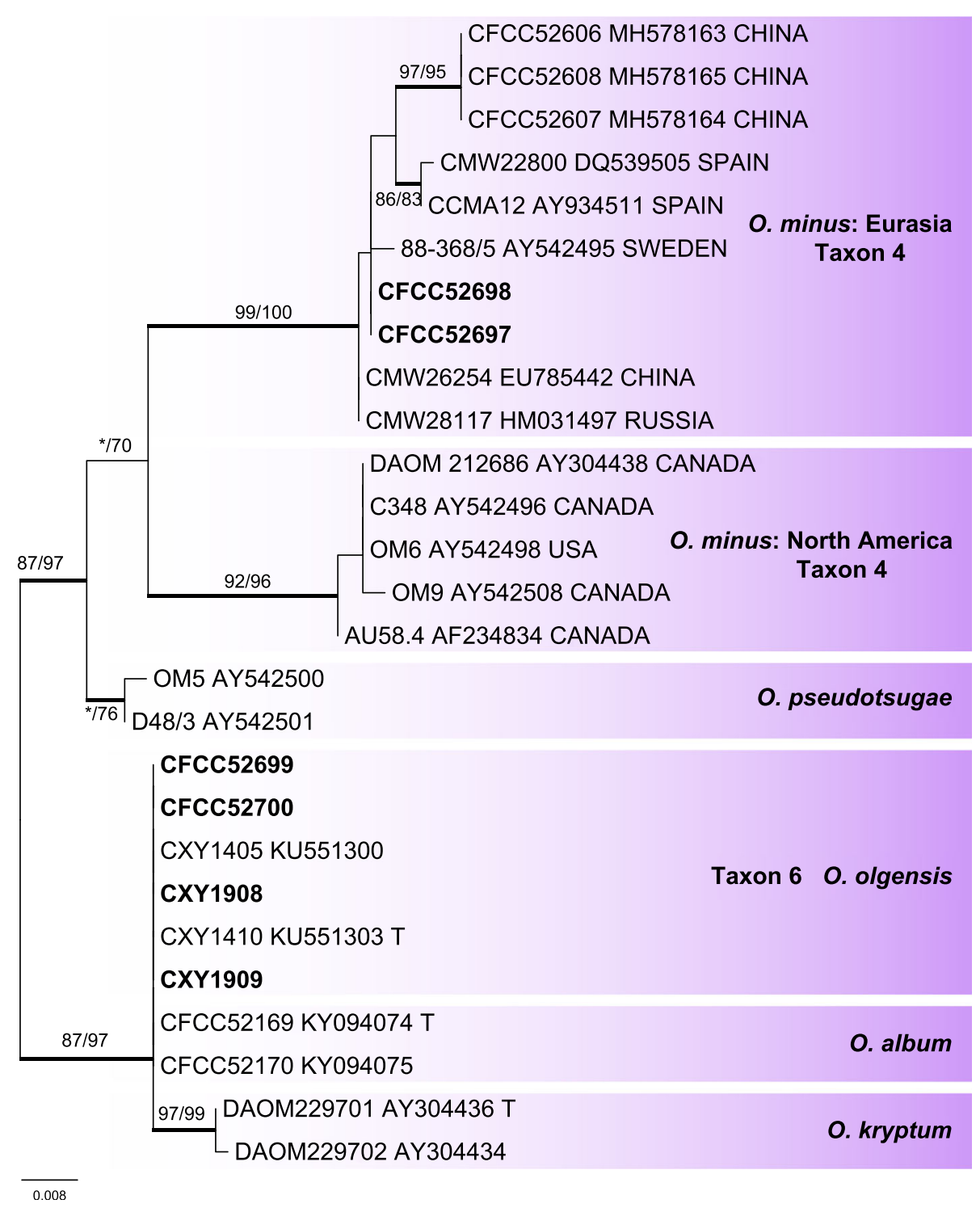

Fig. $4 \mathrm{ML}$ tree of O. minus complex generated from the ITS sequence data. Sequences generated from this study are printed in bold. Bold branches indicate posterior probability values $\geq 0.9$. Bootstrap values of $\mathrm{ML} / \mathrm{MP} \geq 70 \%$ are recorded at the nodes. $T=$ ex-type isolates 


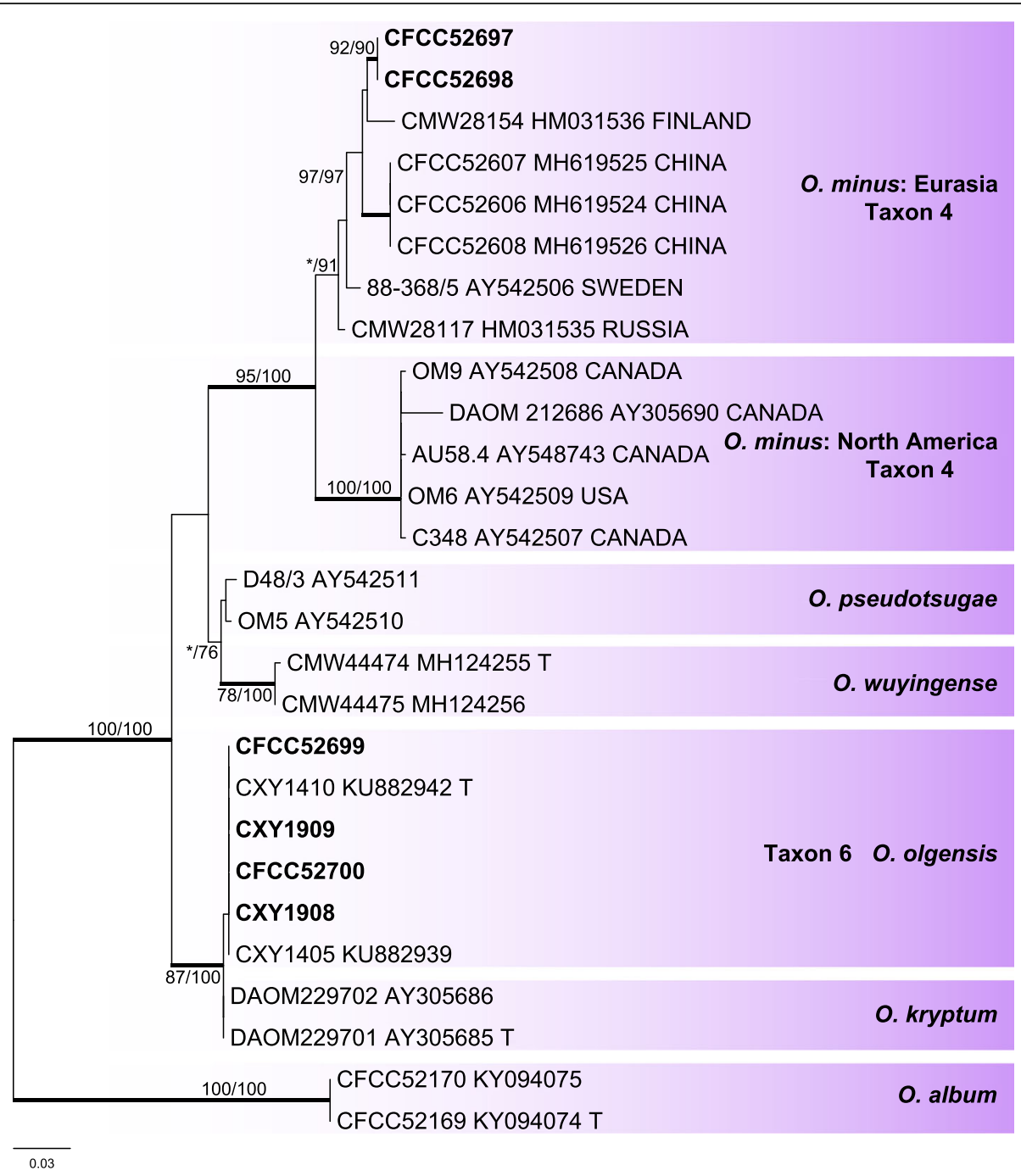

Fig. $5 \mathrm{ML}$ tree of $O$. minus complex generated from the $\beta T$ sequence data. Sequences generated from this study are printed in bold. Bold branches indicate posterior probability values $\geq 0.9$. Bootstrap values of $M L / M P \geq 70 \%$ are recorded at the nodes. $T=$ ex-type isolates

related to the O. brunneo-ciliatum, O. brunneolum, O. clavatum, O. macroclavatum and $O$. pseudocatenulatum species clades.

Six representative strains of taxon 8 in the O. ips complex were used in the analyses. Taxon 8 formed a distinct clade with good statistical support in ITS (Fig. 7) and $\beta \mathrm{T}$ (Fig. 8) analyses. It was closely related to $O$. bicolor.

Two strains of taxon 3 in Group A were used in the analyses. Taxon 3 formed an independent lineage with good support values in ITS and $\beta$ T based phylograms (Figs. 9, 10) and was most closely related to O. saponiodorum and O. pallidulum.

\section{Ceratocystiopsis}

The LSU phylogenetic tree of the genus Ceratocystiopsis did not yield an independent clade for taxon 12 (Fig. 11), although its strains showed clear dissimilarity with $C$. pallidobrunnea in terms of the LSU sequence data. The lack of available reference data in GenBank for other genes for C. pallidobrunnea impeded any closer comparison. Therefore, this species is hitherto recorded as Ceratocystiopsis cf. pallidobrunnea.

\section{Leptographium and Endoconidiophora}

Sequence comparisons and phylogenetic analyses revealed that representative strains of taxa 13 and 14 had identical sequences respectively and clustered into the same clades as Leptographium zhangii and Endoconidiophora fujiensis based on EF- $1 \alpha$ and $60 \mathrm{~S}$ genes (Additional file 8: Figure S7, Additional file 9: Figure S8). Therefore, these two phylogenetic species were defined as the known species previously discovered in China (Meng et al. 2015, Liu et al. 2017). 


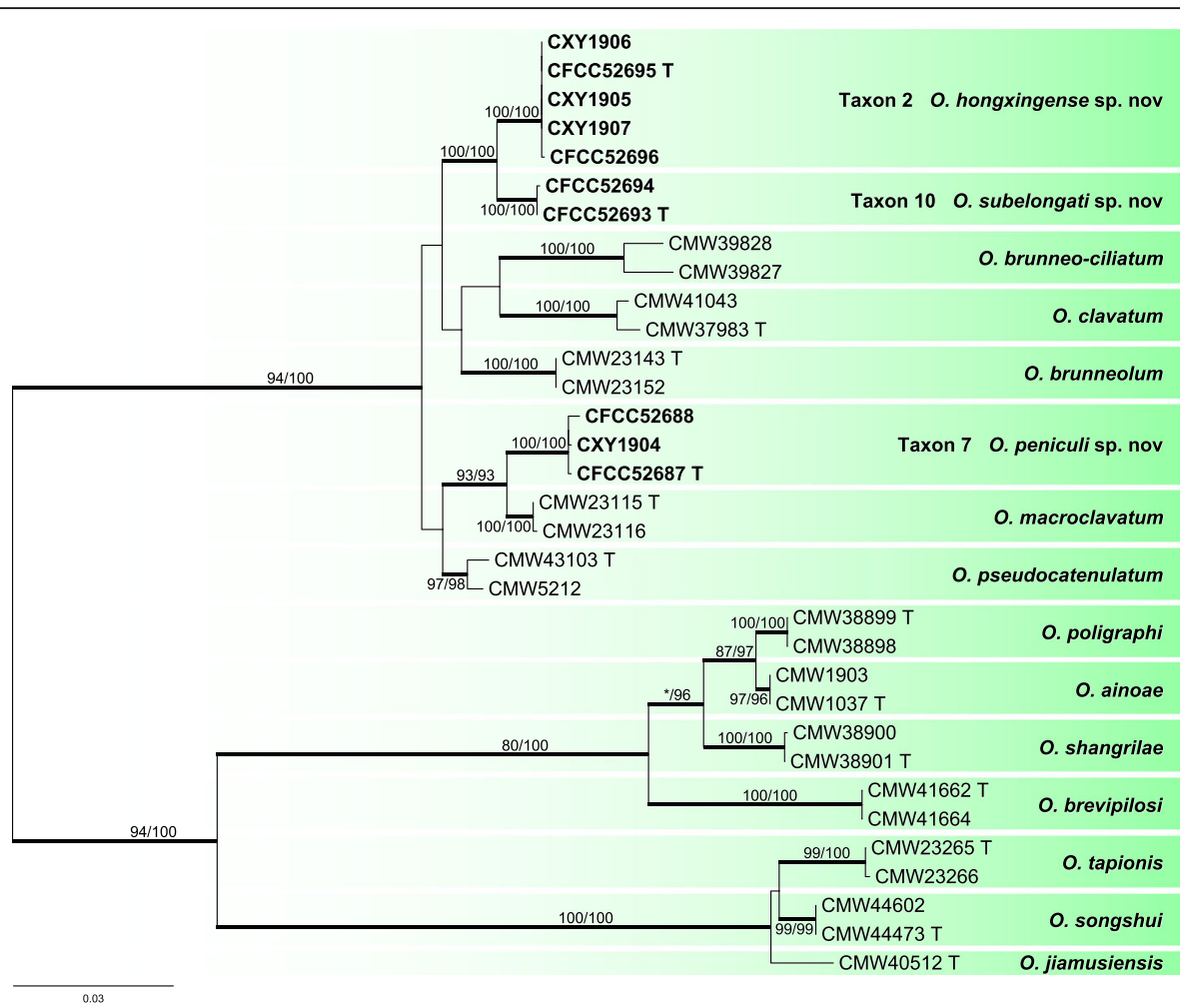

Fig. $6 \mathrm{ML}$ tree of $\mathrm{O}$. clavatum complex generated from the combined ( $\beta T+C A L+E F-1 a)$ sequence data. Sequences generated from this study are printed in bold. Bold branches indicate posterior probability values $\geq 0.9$. Bootstrap values of $M L / M P \geq 70 \%$ are recorded at the nodes. $T=$ ex-type isolates

\section{TAXONOMY}

Eight of 14 phylogenetic species identified in this study were shown to represent distinct terminal clades, and are interpreted as new species of Ophiostoma.

Ophiostoma genhense Z. Wang \& Q. Lu, sp. nov. MycoBank MB 830610.

(Fig. 12)

Etymology: The epithet genhense (Latin) refers to the city of Genhe, from which this fungus was collected.

Diagnosis: The species is characterized by perithecia and synnematous conidiophores. It can be differentiated from the closely related species $O$. multisynnematum by the presence of perithecia, absent in latter, and smaller synnemata. Over time, the $O$. genhense colonies gradually turned brown from the centre, whereas the colonies of $O$. multisynnematum turned dark olivaceous.

Type: China, Inner Mongolia Autonomous Region: Genhe, from Ips subelongatus infesting Larix gmelinii, Sept. 2017, Q. Lu (CXY 2001 - holotype; CFCC 52675 ex-type culture).
Description: Sexual morph perithecial. Perithecia few on $2 \%$ MEA after $20 \mathrm{~d}$, developing on a superficial mycelium or partly embedded in the agar, bases black, (103-) 114-156 (-164) $\mu \mathrm{m}$ diam., with some basal hyphal ornamentation, dark brown to black; necks black, cylindrical, straight or slightly curved, (135-) 210-347 (400) $\mu \mathrm{m}$ long, (17-) 21.5-32.5 $(-38) \mu \mathrm{m}$ wide at the base down to (8.5-) 12.5-17 (-18.5) $\mu \mathrm{m}$ wide at the apex, composed of parallel, septate, laterally fused hyphae, ending in a crown of hyaline. Ostiolar hyphae occasionally present, 6.5-13 (-18) $\mu \mathrm{m}$ long. Ascospores hyaline, allantoid or crescent in side view, without sheath, aseptate, (3.5-) 4-5 (-6) × (1.5-) $2(-2.5) \mu \mathrm{m}$.

Asexual morphs: pesotum-like and hyalorhinocladiellalike.

Pesotum-like morph: synnemata solitary or in groups, the base black, (22.5-) 24.5-45.5 (-48.5) $\mu \mathrm{m}$ wide, (170-) 184-257 (-271) $\mu \mathrm{m}$ tall, including the conidiogenous apparatus. Conidiogenous cells (12-) 15-23 ($26.5) \times 1.5-2 \mu \mathrm{m}$. Conidia hyaline, smooth, cylindrical, aseptate, (3-) 3.5-4 (-4.5) × 2-2.5 $\mu \mathrm{m}$. Hyalorhinocladiella-like morph: conidiogenous cells arising directly 


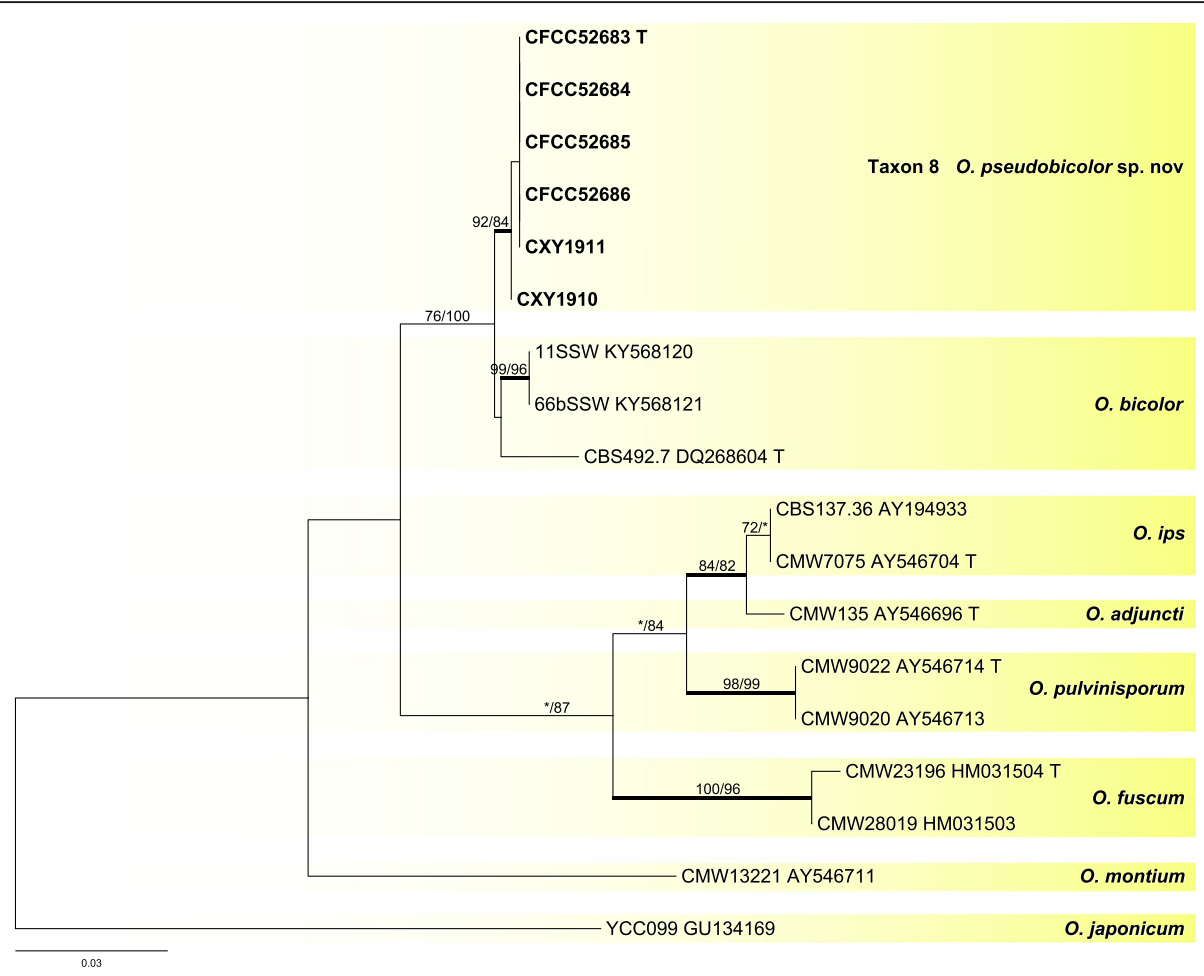

Fig. $7 \mathrm{ML}$ tree of $\mathrm{O}$. ips complex generated from the ITS sequence data. Sequences generated from this study are printed in bold. Bold branches indicate posterior probability values $\geq 0.9$. Bootstrap values of $\mathrm{ML} / \mathrm{MP} \geq 70 \%$ are recorded at the nodes. $T=$ ex-type isolates

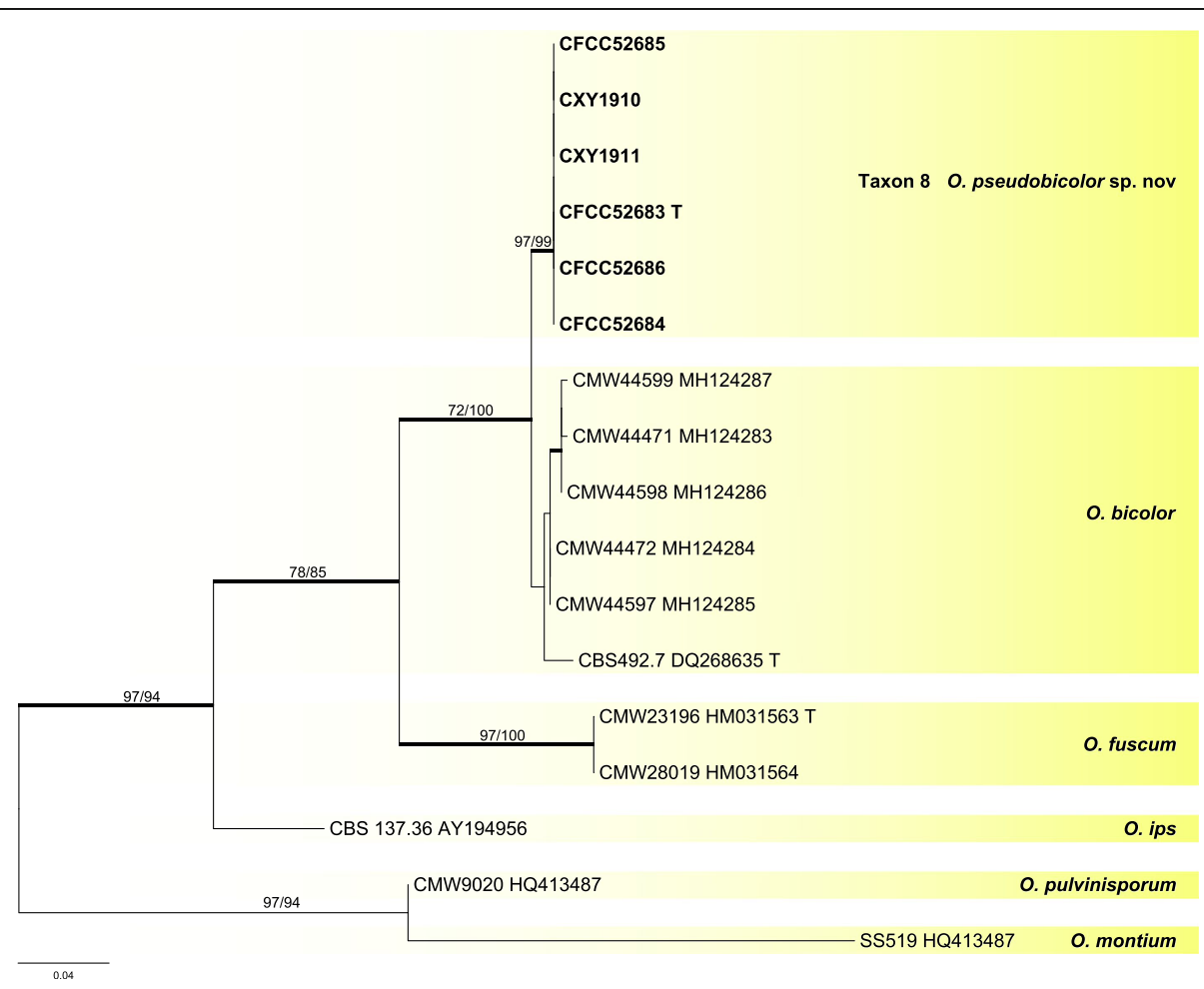

Fig. $8 \mathrm{ML}$ tree of O. ips complex generated from the $\beta T$ sequence data. Sequences generated from this study are printed in bold. Bold branches indicate posterior probability values $\geq 0.9$. Bootstrap values of $\mathrm{ML} / \mathrm{MP} \geq 70 \%$ are recorded at nodes. $T=$ ex-type isolates 


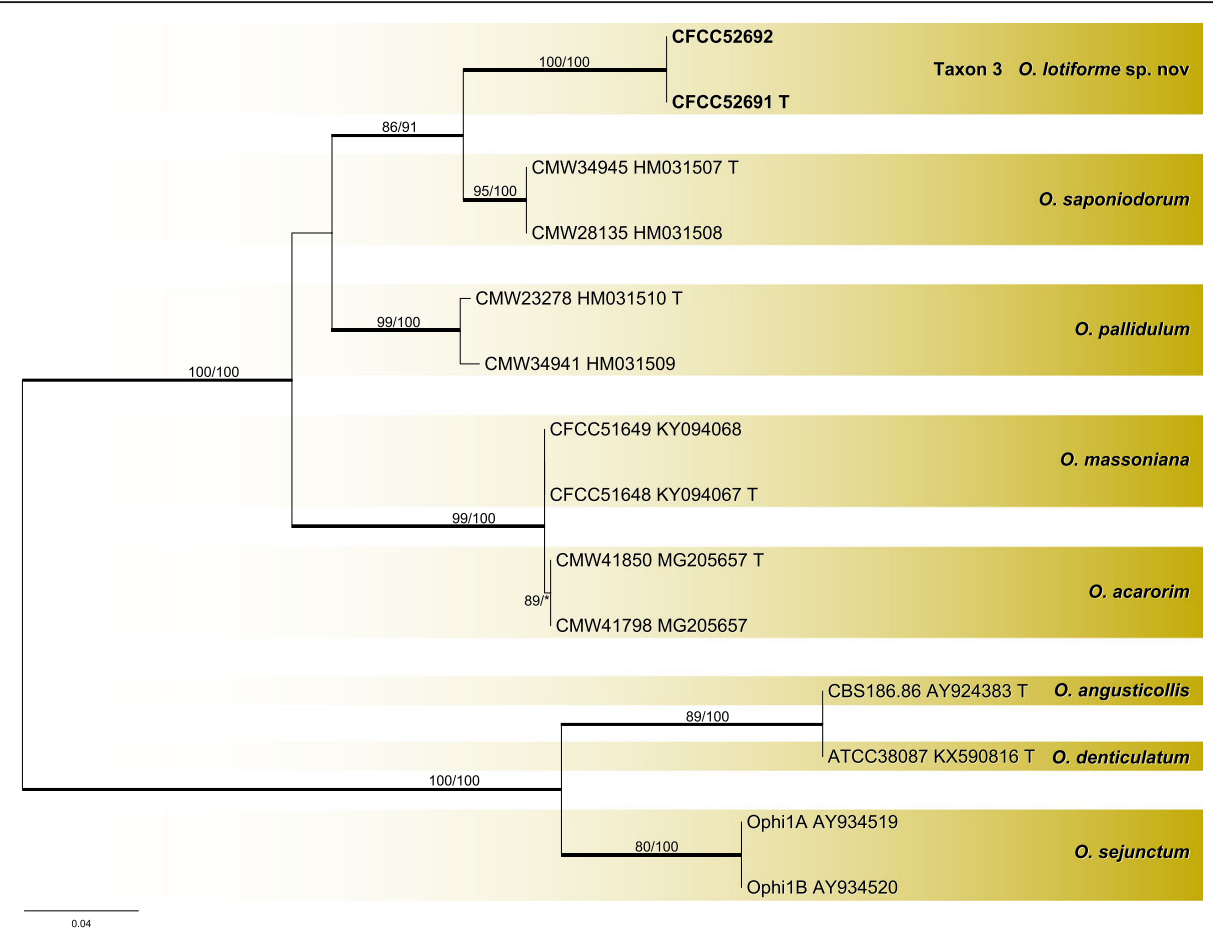

Fig. $9 \mathrm{ML}$ tree of Group A generated from the ITS sequence data. Sequences generated from this study are printed in bold. Bold branches indicate posterior probability values $\geq 0.9$. Bootstrap values of $M L / M P \geq 70 \%$ are recorded at the nodes. $T$ = ex-type isolates

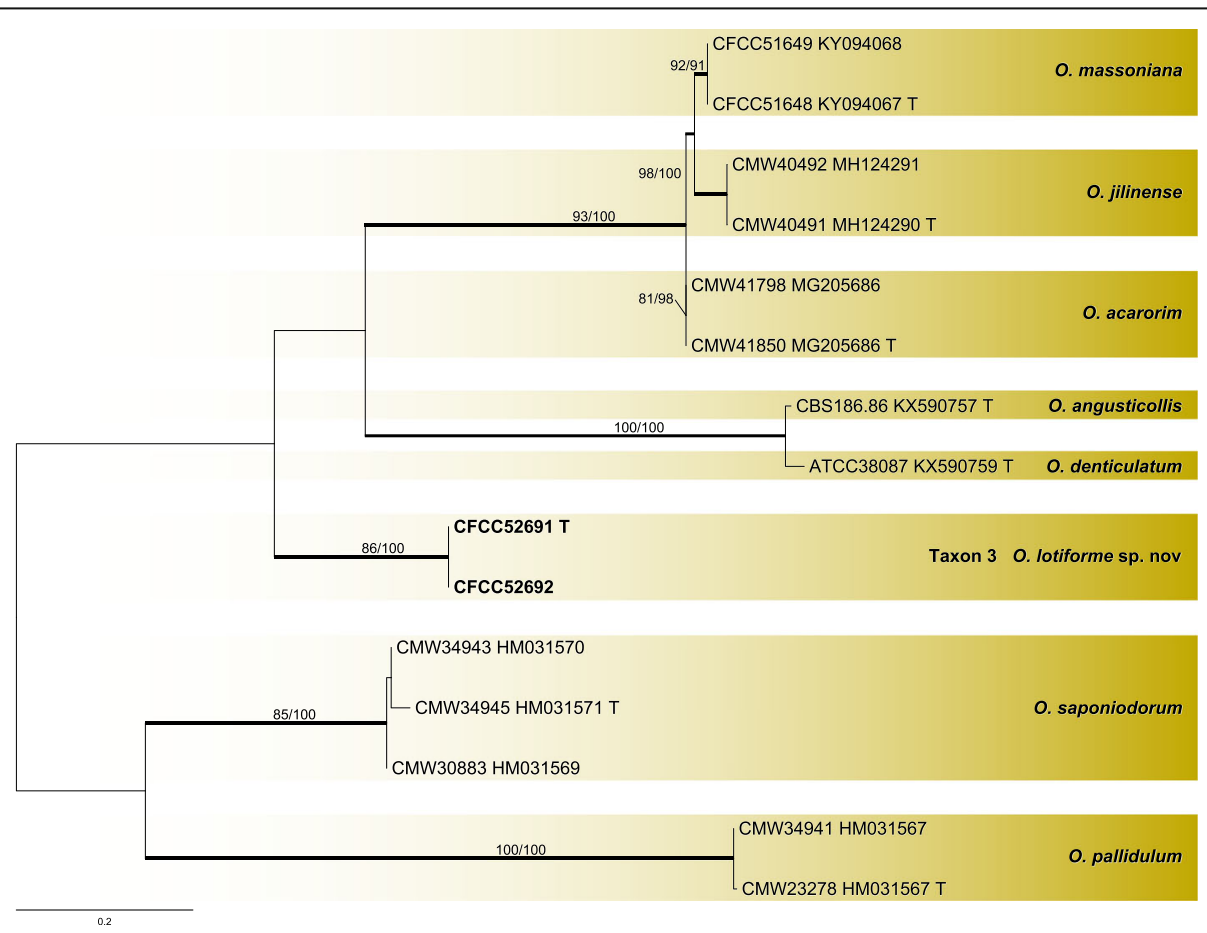

Fig. $10 \mathrm{ML}$ tree of Group A generated from the $\beta T$ sequence data. Sequences generated from this study are printed in bold. Bold branches indicate posterior probability values $\geq 0.9$. Bootstrap values of $\mathrm{ML} / \mathrm{MP} \geq 70 \%$ are recorded at the nodes. $T$ = ex-type isolates 


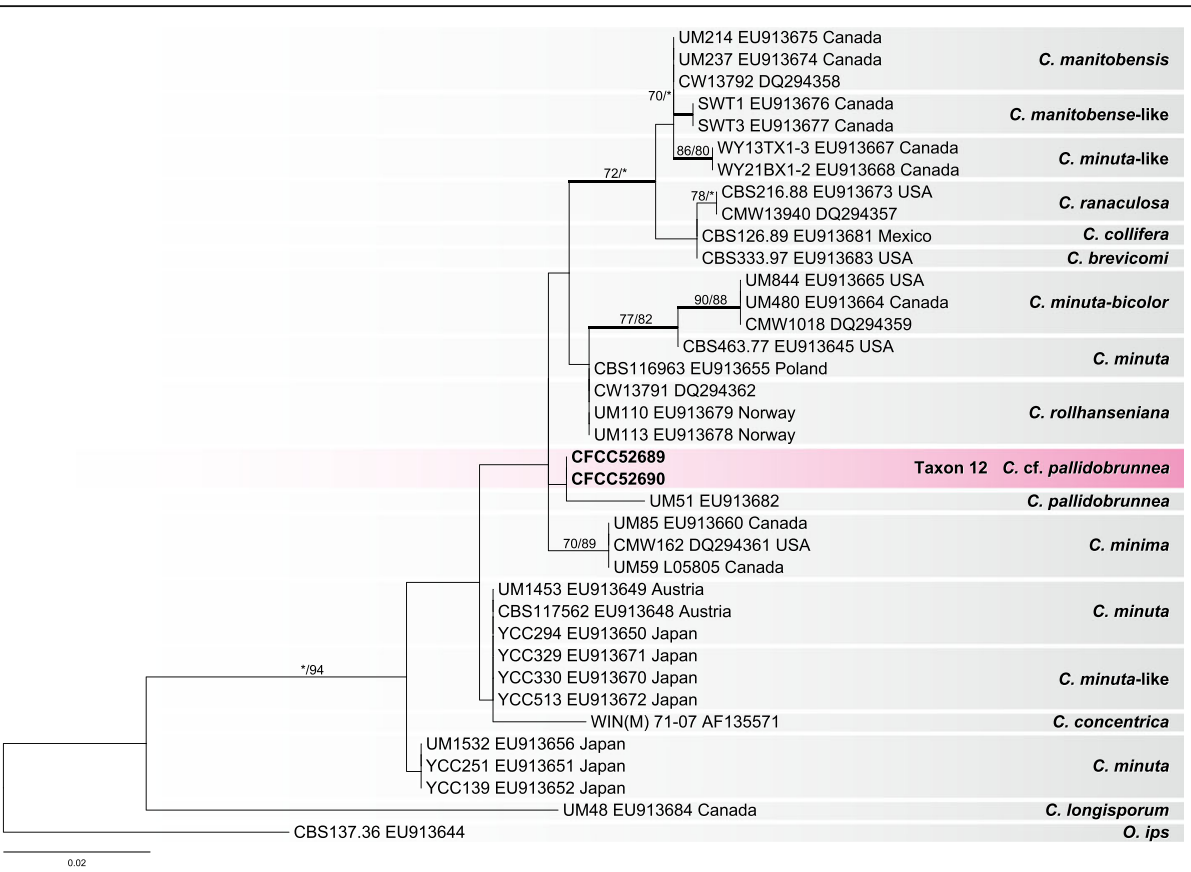

Fig. $11 \mathrm{ML}$ tree of Ceratocystiopsis generated from the LSU sequence data. Sequences generated from this study are printed in bold. Bold branches indicate posterior probability values $\geq 0.9$. Bootstrap values of $\mathrm{ML} / \mathrm{MP} \geq 70 \%$ are recorded at the nodes
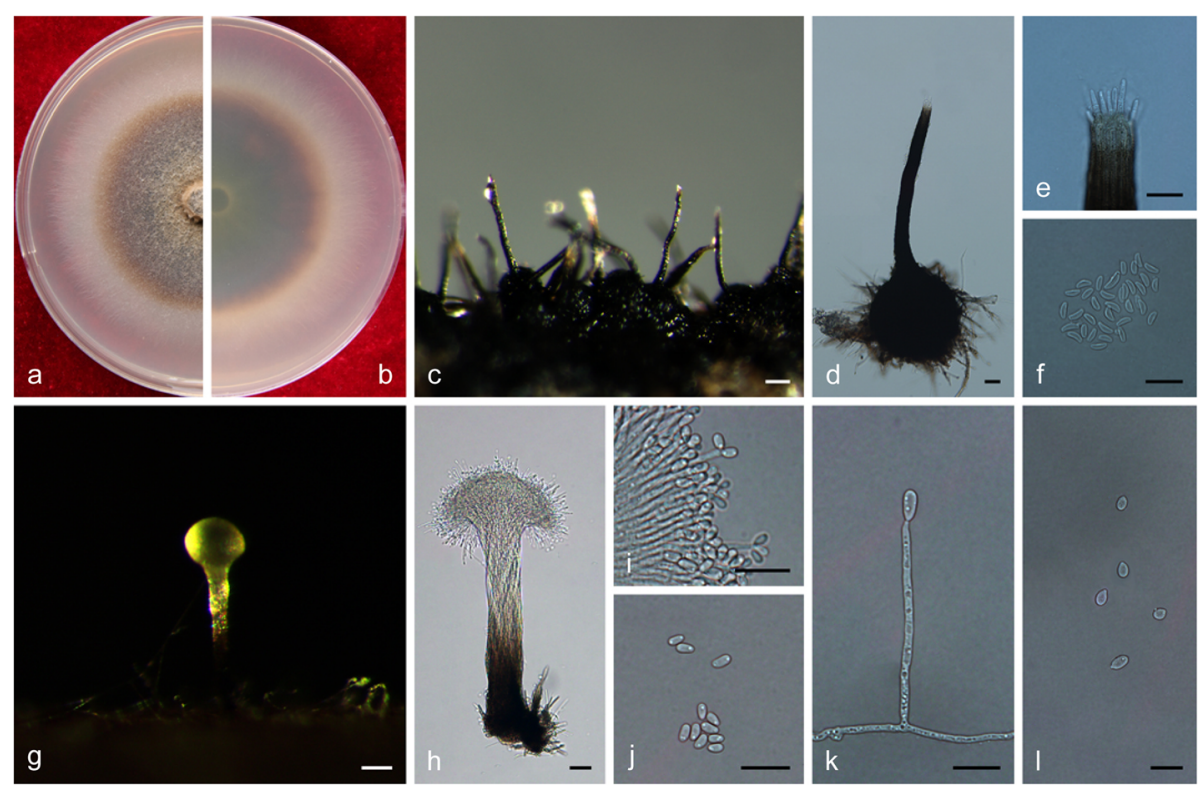

Fig. 12 Morphological characteristics of Ophiostoma genhense sp. nov. (CFCC 52675, Taxon 1). a-b. Ten-day-old cultures on 2\% MEA; c-d. Perithecium. e. Ostiolar hyphae. f. Ascospores. g-h. Pesotum-like asexual morph; $\mathbf{i}-\mathbf{j}$. Conidiogenous cells of pesotum-like asexual morph and conidia; k-l. Hyalorhinocladiella-like asexual morph: conidiogenous cells and conidia. Scale bars: $c=50 \mu \mathrm{m} ; \mathrm{d}=20 \mu \mathrm{m} ; \mathrm{e}-\mathrm{f}=10 \mu \mathrm{m} ; \mathrm{g}=50 \mu \mathrm{m}$; $\mathrm{h}=20 \mu \mathrm{m} ; \mathrm{i}-\mathrm{I}=10 \mu \mathrm{m}$ 
from the hyphae, $(25-) 30.5-43(-44) \times 1.5-2 \mu \mathrm{m}$. Conidia hyaline, smooth, ovate to cylindrical, aseptate, (3.5-) 4-5.5 (-7) × (2.5-) 3-3.5 (-4) $\mu \mathrm{m}$.

Cultures: Colonies on $2 \%$ MEA at $25{ }^{\circ} \mathrm{C}$ reaching $80 \mathrm{~mm}$ diam. in $10 \mathrm{~d}$, initially hyaline, later becoming brown, mycelium superficial or sparsely aerial, the colonies edge thinning radially, synnemata and perithecia scattered in the centre. Optimal temperature for growth at $25^{\circ} \mathrm{C}$, no growth observed at $5{ }^{\circ} \mathrm{C}$ and $35^{\circ} \mathrm{C}$.

Ecology: Isolated from Ips subelongatus infesting dying Larix gmelinii and stock log.

Habitat: L. gmelinii pure plantation.

Distribution: Currently only known from the Inner Mongolia Autonomous Region, China.

Notes: Ophiostoma genhense and O. multisynnematum formed two distinct, well-supported clades within the $O$. piceae complex (Fig. 3), in which they were closely related to O. breviusculum (Chung et al. 2006). They can be both differentiated from $O$. breviusculum by the presence of a hyalorhinocladiella-like asexual state, which is absent in the latter.

Additional specimens examined: China: Inner Mongolia Autonomous Region: Genhe, from Ips subelongatus infesting Larix gmelinii, Sept. 2017, Q. Lu (cultures CXY 2002, CFCC 52676).

Ophiostoma hongxingense Z. Wang \& Q. Lu, sp. nov. MycoBank MB 830611.

(Fig. 13)

Etymology: The epithet hongxingense (Latin) refers to the city of Hongxing, from which this fungus was collected.

Diagnosis: See comparisons between Ophiostoma hongxingense and $O$. subelongati under $O$.
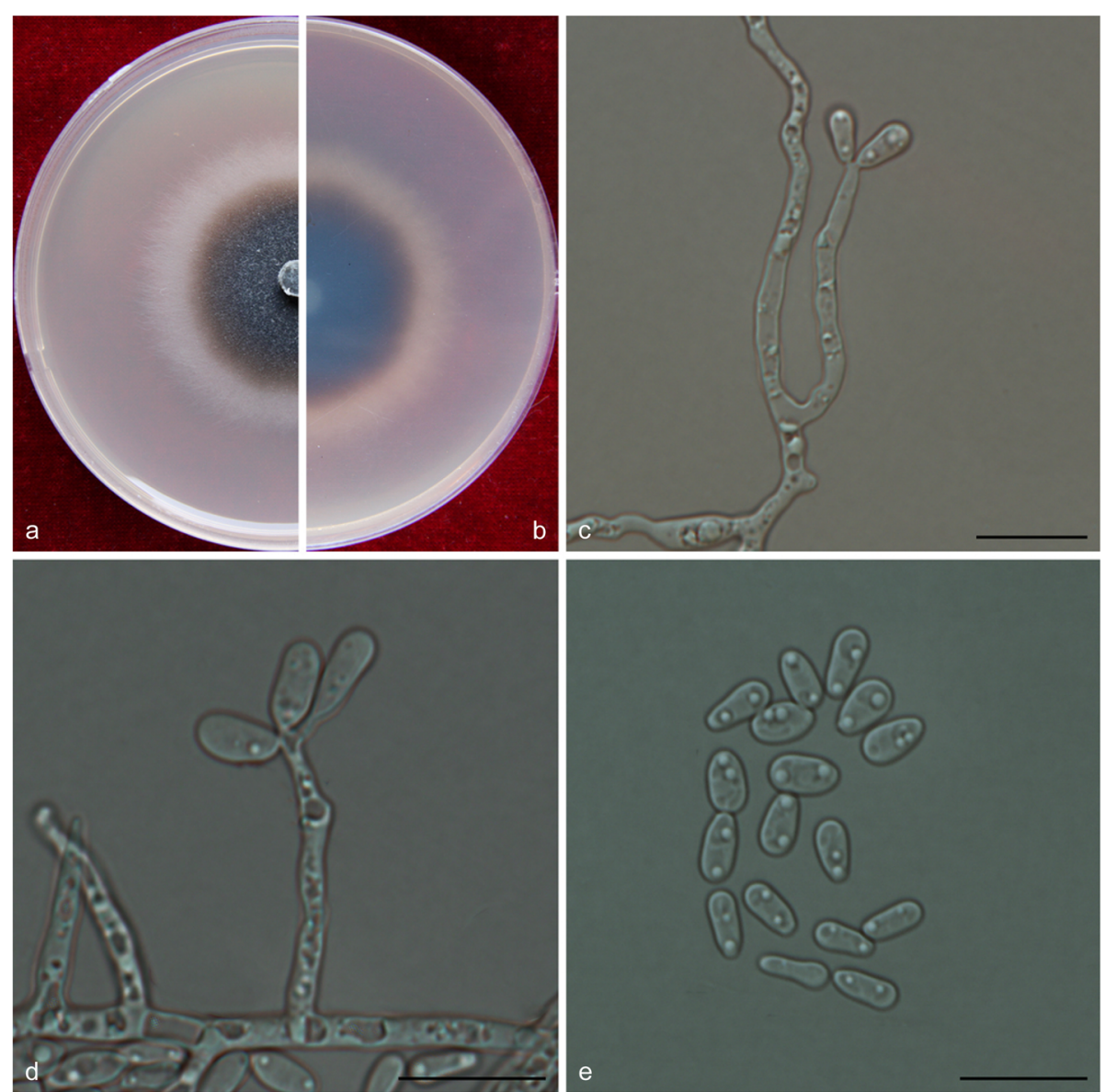

Fig. 13 Morphological characteristics of Ophiostoma hongxingense sp. nov. (CFCC 52695, Taxon 2). a-b. Five-day-old cultures on 2\% MEA; c-e. Hyalorhinocladiella-like asexual morph: conidiogenous cells and conidia. Scale bars: $\mathrm{c}-\mathrm{e}=10 \mu \mathrm{m}$ 
subelongati.

Type: China: Heilongjiang province: Hongxing, from Ips subelongatus on Larix gmelinii, July 2017, Q. Lu (CXY 2021 - holotype; CFCC 52695 - ex-type culture).

Description: Sexual morph not observed.

Asexual morph: hyalorhinocladiella-like.

Hyalorhinocladiella-like morph: conidiogenous cells arising directly from superficial hyphae, (10.5-) 14-22.5 ($28.5) \times(1.5-) 2-2.5(-3) \mu \mathrm{m}$. Conidia hyaline, smooth, ovate to elliptical, aseptate, (5-) 5.5-6.5 (-8) × (2-) 2.5$3.5(-4) \mu \mathrm{m}$.

Cultures: Colonies on $2 \%$ MEA at $25{ }^{\circ} \mathrm{C}$ reaching $58 \mathrm{~mm}$ diam. in $5 \mathrm{~d}$, initially hyaline, discoloring progressively to dark olivaceous from the centre of the colonies to the margin, the colonies edge thinning radially; mycelium superficial on the agar. Optimal temperature for growth at $30^{\circ} \mathrm{C}$, no growth observed at $5^{\circ} \mathrm{C}$ and $40^{\circ} \mathrm{C}$.

Ecology: Isolated from Ips subelongatus infesting dying Larix gmelinii and L. olgensis.

Habitat: L. gmelinii or L. olgensis pure plantation.

Distribution: Currently known from the Inner Mongolia Autonomous Region and Heilongjiang province, China.

Notes: See comparisons between Ophiostoma hongxingense and $O$. subelongati under O. subelongati.

Additional specimens examined: China: Heilongjiang province, Zhanhe, from Ips subelongatus infesting Larix gmelinii, July 2017, Q. Lu (cultures CXY 2022 = CFCC 52696; CXY 1905; CXY 1906; CXY 1907); Jiamusi, from

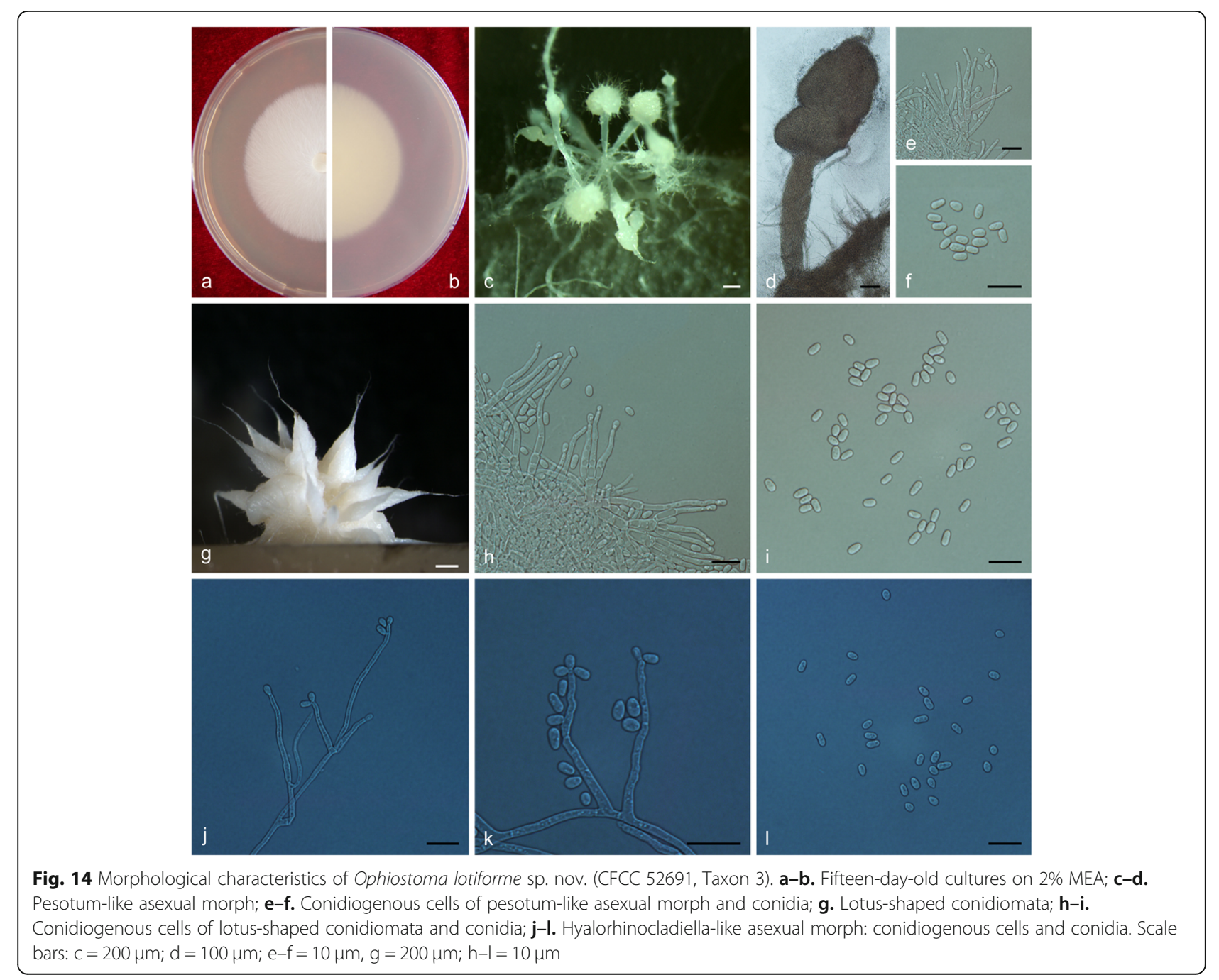


Ips subelongatus infesting Larix olgensis. Aug. 2011, Q. Lu (culture CXY 1924).

Ophiostoma lotiforme Z. Wang \& Q. Lu, sp. nov. MycoBank MB 830612.

(Fig. 14)

Etymology: The epithet lotiforme (Latin) refers to lotusshaped conidiomata composed of clustered synnemata.

Diagnosis: The compound, lotus-shaped conidiomata are unique, and its synnemata are distinctly taller than those of the related species $O$. saponiodorum, respectively (876-) 945-1224 (-1290) $\mu \mathrm{m}$ vs. (118-) 188-297 $(-370) \mu \mathrm{m}$. Synnemata are absent in O. pallidulum (Linnakoski et al. 2010). Ophiostoma lotiforme also grows slower than O. saponiodorum on $2 \%$ MEA. In addition, no growth of $O$. saponiodorum is observed at $35^{\circ} \mathrm{C}$, but $O$. lotiforme grows at $35^{\circ} \mathrm{C}$; no growth of $O$. lotiforme is observed at $40^{\circ} \mathrm{C}$, but $O$. pallidulum grows at $40^{\circ} \mathrm{C}$.

Type: China: Inner Mongolia Autonomous Region, Hailar, from Ips subelongatus on Pinus sylvestris var. mongolica, Aug. 2010, X. Meng (CXY 2017 - holotype, CFCC 52691 = MUCL 55165 - ex-type culture).

Description: Sexual morph not observed.
Asexual morphs: pesotum-like and hyalorhinocladiellalike.

Pesotum-like morph: synnemata occurring in groups, the base hyaline, (78.5-) 81.5-91.5 (-94) $\mu \mathrm{m}$ wide, (876-) 945-1224 (-1290) $\mu \mathrm{m}$ tall including the conidiogenous apparatus. Conidiogenous cells (12-) 15-23 ($28.5) \times(1.5-) 2-2.5 \mu \mathrm{m}$. Conidia hyaline, smooth, clavate to ovate, aseptate, $4-5.5(-6) \times 2-2.5 \mu \mathrm{m}$; compound, lotus-shaped, pesotum-like conidiomata, pure white, (898-) 971-1296 (-1450) $\mu \mathrm{m}$ wide at base, (964-) 1019-1427 (-1655) $\mu \mathrm{m}$ tall. Hyalorhinocladiella-like morph: conidiogenous cells arising from superficial hyphae, $(6-)$ 11-22 $(-28.5) \times 1.5-2.5(-3) \mu \mathrm{m}$. Conidia hyaline, aseptate, smooth, clavate to ovate, (3.5-) 4-5.5 $(-6.5) \times(2-) 2.5-3.5(-4) \mu \mathrm{m}$.

Cultures: Colonies on $2 \%$ MEA at $25^{\circ} \mathrm{C}$ reaching $65 \mathrm{~mm}$ diam. in $15 \mathrm{~d}$, pure white, the colonies margin smooth; mycelium superficial on the agar. Optimal temperature for growth at $30^{\circ} \mathrm{C}$, no growth observed at $5{ }^{\circ} \mathrm{C}$ and $40{ }^{\circ} \mathrm{C}$.

Ecology: Isolated from Ips subelongatus infesting dying Pinus sylvestris var. mongolica.

Habitat: Mixed forest of P. sylvestris var. mongolica and L. gmelinii.
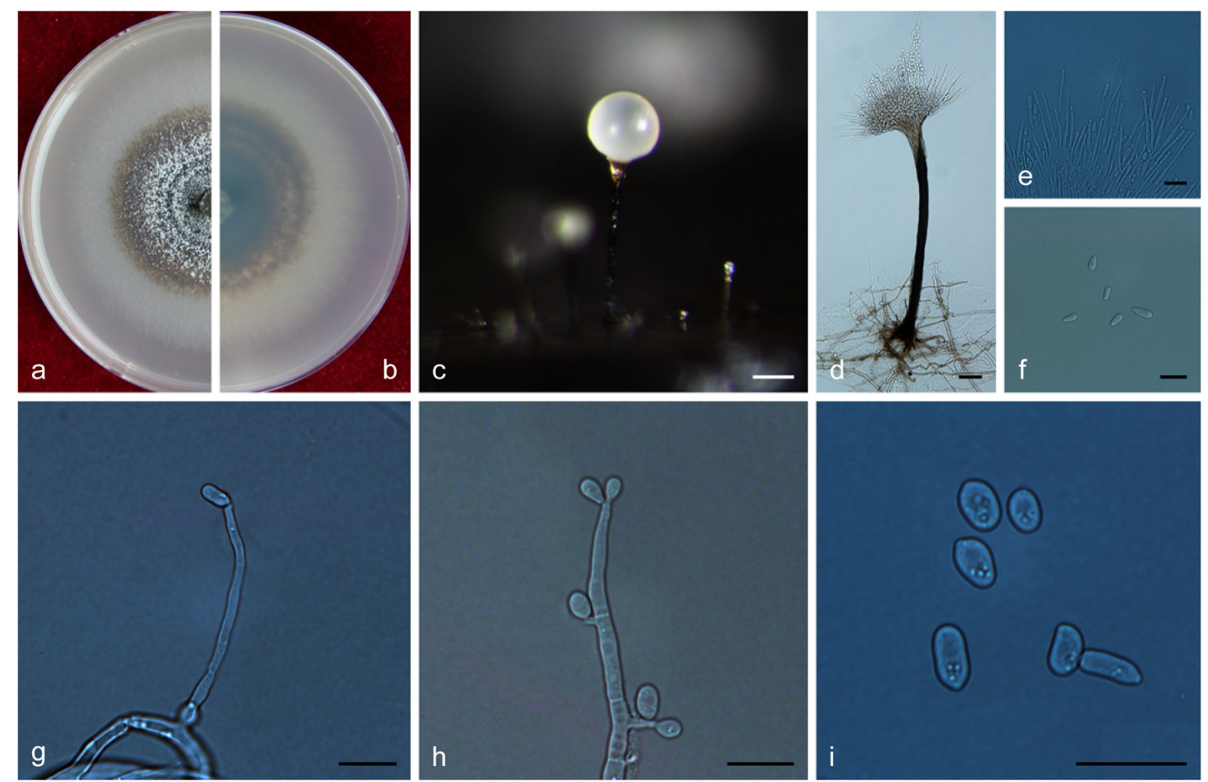

Fig. 15 Morphological characteristics of Ophiostoma multisynnematum sp. nov. (CFCC 52677, Taxon 5). a-b. Ten-day-old cultures on 2\% MEA; cd. Pesotum-like asexual morph; e-f. Conidiogenous cells of pesotum-like asexual morph and conidia; $\mathbf{g - i}$. Hyalorhinocladiella-like asexual morph: conidiogenous cells and conidia. Scale bars: $c=50 \mu \mathrm{m} ; \mathrm{d}=20 \mu \mathrm{m} ; \mathrm{e}-\mathrm{i}=10 \mu \mathrm{m}$ 
Distribution: Currently only known from the Inner Mongolia Autonomous Region, China.

Notes: Ophiostoma lotiforme pertains to the O. saponiodorum lineage, in which it is closely related to O. saponiodorum and O. pallidulum (Figs. 2, 9, and 10). These species share a hyalorhinocladiella-like asexual state (Linnakoski et al. 2010).

Additional specimens examined: China: Inner Mongolia Autonomous Region, Hailar, from Ips subelongatus infesting Pinus sylvestris var. mongolica, Aug. 2010, X. Meng (cultures CXY 2018 = CFCC 52692).

Ophiostoma multisynnematum Z. Wang \& Q. Lu, sp. nov.

MycoBank MB 830614.

(Fig. 15)

Etymology: The epithet multisynnematum (Latin) referring to the numerous synnemata.

Diagnosis: See comparisons among Ophiostoma multisynnematum, O. genhense, and O. breviusculum below the description of $O$. genhense.

Type: China: Inner Mongolia Autonomous Region, Genhe, from Ips subelongatus infesting Larix gmelinii, Sept. 2017, Q. Lu (CXY 2003 - holotype; CFCC 52677 ex-type culture).

Description: Sexual morph not observed.
Asexual morphs: pesotum-like and hyalorhinocladiellalike.

Pesotum-like morph: synnemata occurring singly or in groups, the base black, (11-) 12.5-43.5 (-73) $\mu \mathrm{m}$ wide, (256-) 307-433 (-544) $\mu \mathrm{m}$ tall including conidiogenous apparatus. Conidiogenous cells (12-) 17.5-31.5 (-45) $\times$ 1.5-2 (-2.5) $\mu \mathrm{m}$. Conidia hyaline, smooth, cylindrical, aseptate, 5.5-7 (-8.5) × (2-) 2.5-3 (-3.5) $\mu \mathrm{m}$. Hyalorhinocladiella-like morph: conidiogenous cells arising from superficial hyphae, (9-) 13-33.5 (-50.5) × (1.5-) 2-2.5 (-3) $\mu \mathrm{m}$. Conidia hyaline, smooth, ovate to cylindrical, aseptate, (4-) 4.5-5.5 (-6.5) × 2.5-3.5 (-4.5) $\mu \mathrm{m}$.

Cultures: Colonies on $2 \%$ MEA at $25^{\circ} \mathrm{C}$ reaching $78 \mathrm{~mm}$ in diameter in $10 \mathrm{~d}$, initially hyaline, thinning radially toward the margin, later becoming dark olivaceous and massive synnemata arising in the centre; hyphae superficial, aerial mycelium sparse. Optimal temperature for growth at $25^{\circ} \mathrm{C}$, no growth observed at $5^{\circ} \mathrm{C}$ and $35^{\circ} \mathrm{C}$.

Ecology: Isolated from Ips subelongatus infesting dying Larix gmelinii and stock log.

Habitat: L. gmelinii pure plantation.

Distribution: Currently only known from the Inner Mongolia Autonomous Region, China.

Notes: See comparisons among Ophiostoma multisynnematum, O. genhense, and O. breviusculum below the
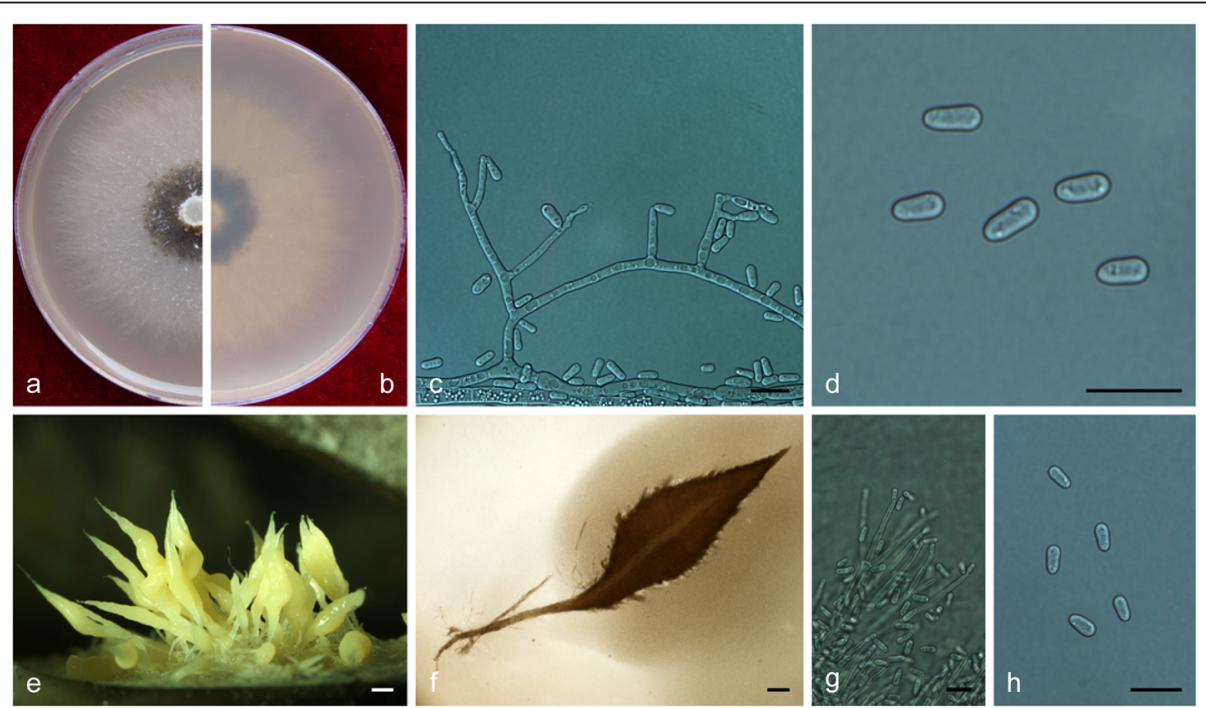

Fig. 16 Morphological characteristics of Ophiostoma peniculi sp. nov. (CFCC 52687, Taxon 7). a-b. Five-day-old cultures on 2\% MEA; c-d. Hyalorhinocladiella-like asexual morph: conidiogenous cells and conidia. e. Brush-like conidioma; $\mathbf{f}$. Pesotum-like asexual morph; g-h. Conidiogenous cells of pesotum-like asexual morph and conidia. Scale bars: $c-d=10 \mu m ; e=400 \mu m ; f=200 \mu m ; g-h=10 \mu m$ 
description of O. genhense.

Additional specimens examined: China: Inner Mongolia Autonomous Region, Genhe, from Ips subelongatus infesting Larix gmelinii, Sept. 2017, Q. Lu (cultures CXY 2004 = CFCC 52678; CXY 1917; CXY 1918; CXY 1919).

Ophiostoma peniculi Z. Wang \& Q. Lu, sp. nov. MycoBank MB 830609.

(Fig. 16)

Etymology: The epithet peniculi (Latin) refers to the brush-like conidiomata.

Diagnosis: Ophiostoma peniculi, O. macroclavatum, and O. pseudocatenulatum can be distinguished from each other by the sizes of their synnemata and conidia. In decreasing order, the size ranges of their synnemata are (2184-) 3117-5172 (-6330) $\mu \mathrm{m}$ in O. macroclavatum, (1366-) 1931-3696 (-4534) $\mu \mathrm{m}$ in O. pseudocatenulatum and (875) 945-1224 (-1290) $\mu \mathrm{m}$ in O. peniculi. The width ranges of their conidia are, in decreasing order, $2-2.5 \mu \mathrm{m}$ in O. peniculi, $1.5-2(-3) \mu \mathrm{m}$ in $O$. macroclavatum, and (0.5-) 1-1.5 (-2) $\mu \mathrm{m}$ in O. pseudocatenulatum. Ophiostoma peniculi colonies also grow faster than the above two species on $2 \%$ MEA at $25^{\circ} \mathrm{C}$. The optimal growth temperature is also different for O. peniculi $\left(30^{\circ} \mathrm{C}\right)$ and $O$. macroclavatum $\left(25^{\circ} \mathrm{C}\right)$. As for O. peniculi, no growth was observed at $5^{\circ} \mathrm{C}$ and $40^{\circ} \mathrm{C}$, but $O$. pseudocatenulatum can still grow at $5^{\circ} \mathrm{C}$ (Linnakoski et al. 2016).
Type: China: Heilongjiang province, Hongxing, from Ips subelongatus infesting Larix gmelinii, Sept. 2017, Q. Lu (CXY 2013 - holotype, CFCC 52687 - ex-type culture).

Description: Sexual morph not observed.

Asexual morphs: pesotum-like and hyalorhinocladiellalike.

Pesotum-like morph: synnemata brush-like, occurring in groups, milky white, (875-) 945-1225 (-1290) $\mu \mathrm{m}$ long including conidiogenous apparatus, (78.5-) 81.591.5 (-94) $\mu \mathrm{m}$ wide at base. Conidiogenous cells (13.5-) 17.5-26.5 $(-32) \times(1.5-) \quad 2-2.5 \mu \mathrm{m}$. Conidia hyaline, smooth, cylindrical, aseptate, (4-) 5-6 $(-6.5) \times 2-$ $2.5 \mu \mathrm{m}$. Hyalorhinocladiella-like morph: conidiogenous cells arising directly from aerial hyphae, (7.5-) 10.5-21 $(-33.5) \times(1.5-) 2-2.5(-3) \mu \mathrm{m}$. Conidia hyaline, aseptate, smooth, cylindrical, (5-) 5.5-6.5 (-8) $\times(28-)$ 2.5$3.5(-4) \mu \mathrm{m}$.

Cultures: Colonies on $2 \%$ MEA at $25^{\circ} \mathrm{C}$ reaching $75 \mathrm{~mm}$ diam. in $5 \mathrm{~d}$, initially hyaline, the colonies edge thinning radially, becoming dark olivaceous in the centre; mycelium mostly superficial, sparsely aerial. Optimal temperature for growth at $30^{\circ} \mathrm{C}$, no growth observed at $5^{\circ} \mathrm{C}$ and $40^{\circ} \mathrm{C}$.

Ecology: Isolated from Ips subelongatus infesting dying Larix gmelinii and L. olgensis.
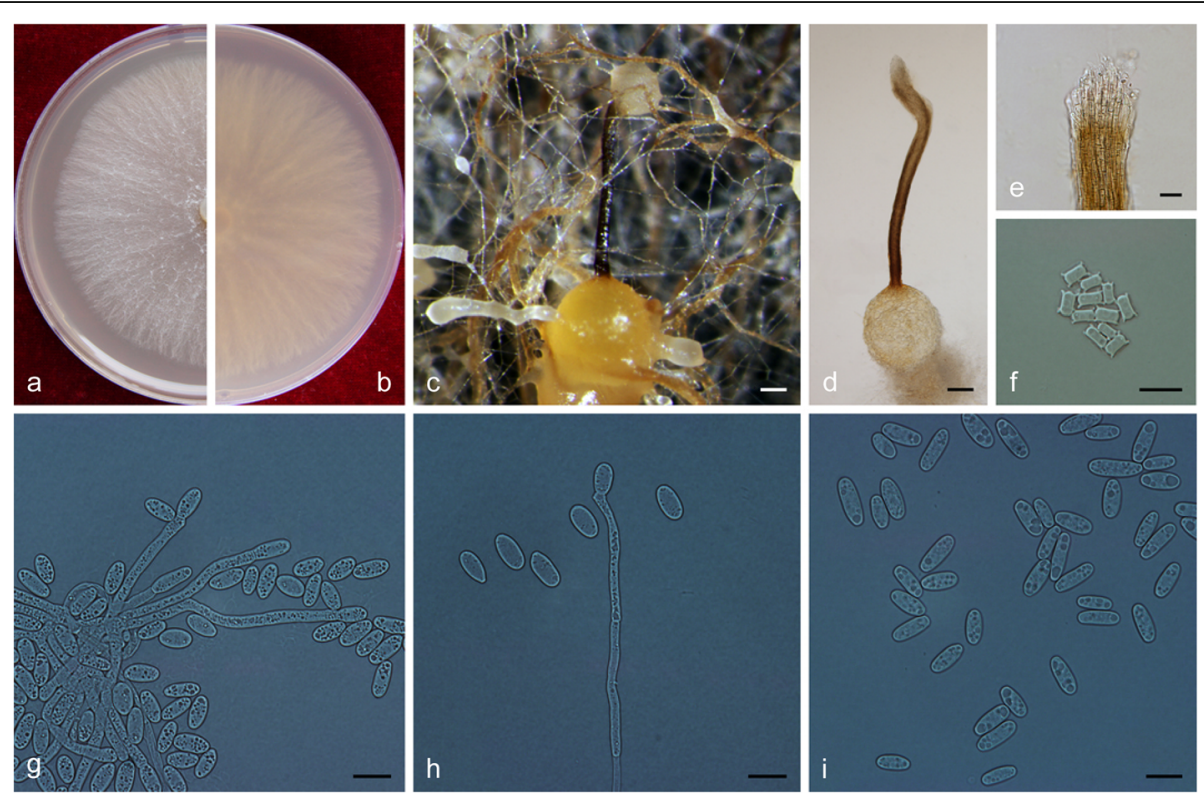

Fig. 17 Morphological characteristics of Ophiostoma pseudobicolor sp. nov. (CFCC 52683, Taxon 8). a-b. Five-day-old cultures on 2\% MEA; c-d Perithecium. e. Apex of perithecium. f. Ascospores. $\mathbf{g - i}$. Hyalorhinocladiella-like asexual morph: conidiogenous cells and conidia. Scale bars: $\mathbf{c}-\mathrm{d}=$ $100 \mu \mathrm{m} ; \mathrm{e}=20 \mu \mathrm{m} ; \mathrm{f}-\mathrm{i}=10 \mu \mathrm{m}$ 
Habitat: L. gmelinii or L. olgensis pure plantation.

Distribution: Currently known from the Inner Mongolia Autonomous Region and Heilongjiang province, China.

Notes: In a phylogenetic perspective, O. peniculi is closely related to $O$. hongxingense, $O$. subelongati, $O$. macroclavatum, O. pseudocatenulatum, and O. brunneolum (Fig. 6). Ophiostoma peniculi is characterized by brush-like synnemata, which are absent in O. hongxingense, O. subelongati (see below), and O. brunneolum (Linnakoski et al. 2016).

Additional specimens examined: China: Heilongjiang province, Zhanhe, from Ips subelongatus infesting Larix gmelinii, Sept. 2017, Q. Lu (cultures CXY $2014=$ CFCC 52688; CXY 1904); Jiamusi, from Ips subelongatus infesting Larix olgensis, Aug. 2011, Q. Lu (culture CXY 1920).

Ophiostoma pseudobicolor Z. Wang \& Q. Lu, sp. nov.

MycoBank MB 830615.

(Fig. 17)

Etymology: The epithet pseudobicolor (Latin) refers to the morphological resemblance and phylogenetic affinities with $O$. bicolor.

Diagnosis: Ophiostoma pseudobicolor is the closest phylogenetic relative to O. bicolor. Morphologically, these two species differ by the size of their perithecia, with globose bases ranging from (308-) 350-480 (-536) $\mu \mathrm{m}$ in O. pseudobicolor vs. $175-350(-365) \mu \mathrm{m}$ in $\mathrm{O}$. bicolor (Upadhyay 1981). The necks of O. pseudobicolor are more robust than those of $O$. bicolor, especially at the apex [viz. (43-) 49-68 (-77) $\mu \mathrm{m}$ vs. 15-42 (-50) $\mu \mathrm{m}]$.
Type: China: Inner Mongolia Autonomous Region, Genhe, from Ips subelongatus infesting Larix gmelinii, Sept. 2017, Q. Lu (CXY 2009 - holotype, CFCC 52683 ex-type culture).

Description: Sexual morph perithecial. Perithecia developing on $2 \%$ MEA at $25^{\circ} \mathrm{C}$ after $15 \mathrm{~d}$ from superficial or embedded mycelium, superficial or partly embedded in the agar medium, with the base globose, subhyaline to yellow orange, (309-) 350-480 (-536) $\mu \mathrm{m}$ diam., extending into a filiform neck; bases globose, prolonged by a cylindrical, straight or slightly curved, occasionally twinning neck, black (663-) 754-1100 (1358) $\mu \mathrm{m}$ long, (33-) 55$77(-79) \mu \mathrm{m}$ wide at the base down to (43-) 49-68 (-77) $\mu \mathrm{m}$ wide at the apex, composed of densely packed septate hyphae with a parallel orientation. Ostiolar hyphae absent. Ascospores hyaline, elliptical to oblong with obtuse ends in side and face view, circular in pole view, surrounded by a thick, hyaline gelatinous sheath appearing ossiform in side and face views, quadrangular with flanged corners in the end view, aseptate, (5.5-) 6-6.5 (-7) × (3-) 3.5-4 (-4.5) $\mu \mathrm{m}$, included sheath.

\section{Asexual morph: hyalorhinocladiella-like.}

Hyalorhinocladiella-like morph: conidiogenous cells arising directly from the hyphae, (14-) 21.5-43.5 ($60.5) \times(2-) 2.5-4(-4.5) \mu \mathrm{m}$. Conidia hyaline, smooth, cylindrical, aseptate, $(8.5-) 10-12(-13) \times(4-) 4.5-5.5$ $(-6) \mu \mathrm{m}$

Cultures: Colonies on $2 \%$ MEA at $25^{\circ} \mathrm{C}$, fast growing, reaching $80 \mathrm{~mm}$ diam. in $5 \mathrm{~d}$, effuse, cottony, hyaline to white at first, becoming white gray or gray brown; hyphae submerged in agar with many aerial mycelium. Optimal temperature for growth at $30^{\circ} \mathrm{C}$, no growth observed at $5^{\circ} \mathrm{C}$ or $40^{\circ} \mathrm{C}$.
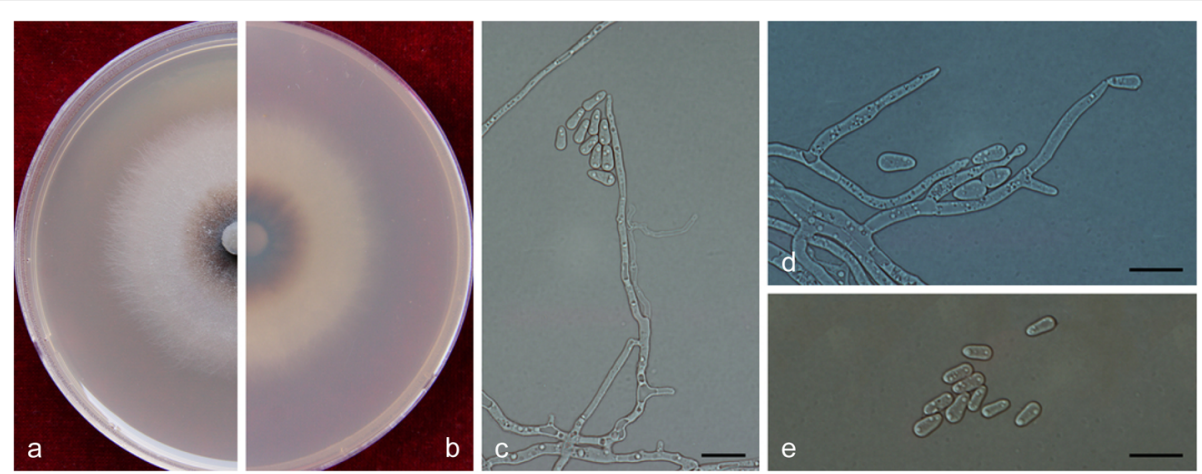

Fig. 18 Morphological characteristics of Ophiostoma subelongati sp. nov. (CFCC 52693, Taxon 10). a-b. Five-day-old cultures on 2\% MEA; c-e. Hyalorhinocladiella-like asexual morph: conidiogenous cells and conidia. Scale bars: $\mathrm{c}-\mathrm{e}=10 \mu \mathrm{m}$ 
Ecology: Isolated from Ips subelongatus infesting dying Larix gmelinii, L. olgensis and L. principis-rupprechtii.

Habitat: L. gmelinii, L. olgensis or L. principis-rupprechtii pure plantation.

Distribution: Currently known from the Inner Mongolia Autonomous Region and Heilongjiang province, China.

Notes: Ophiostoma pseudobicolor is characterized by perithecium with a light-colored base extending into a dark neck. Similarly colored perithecia have been identified in O. bicolor (Upadhyay 1981), which also is the closest phylogenetic relative to O. pseudobicolor (Figs. 7, 8). However, DNA sequences of ITS and $\beta$ T (Figs. 7, 8) clearly showed that both species represent two distinct clades.

Additional specimens examined: China: Inner Mongolia Autonomous Region, Genhe, from Ips subelongatus infesting Larix gmelinii, Sept. 2017, Q. Lu (cultures CXY 2010; CFCC 52684); Chifeng, from Ips subelongatus infesting Larix principis-rupprechtii, Aug. 2011, Q. Lu (cultures CFCC 52685; CXY 2011=MUCL 55168; 1910); Heilongjiang, Mohe, from Ips subelongatus infesting Larix principis-rupprechtii, May 2012, Q. Lu (cultures CFCC 52686; CXY $2012=$ MUCL 55174); Tahe, from Ips subelongatus infesting Larix gmelinii, May 2012, Q. Lu (culture CXY 1911 = MUCL 55170); Jiamusi, from Ips subelongatus infesting Larix olgensis, Aug.
2011, Q. Lu (culture CXY 1925; CXY1926).

Ophiostoma subelongati Z. Wang \& Q. Lu, sp. nov. MycoBank MB 830616.

(Fig. 18)

Etymology: The epithet subelongati (Latin) refers to the vector (Ips subelongatus) from which this fungus was isolated.

Diagnosis: Ophiostoma subelongati colonies gradually turned brownish grey from the centre, but the O. hongxingense colonies centre turned dark olivaceous.

Type: China: Heilongjiang province, Hongxing, from Ips subelongatus infesting Larix gmelinii. July 2017, Q. Lu (CXY 2019 - holotype, CFCC 52693 - ex-type culture).

Description: Sexual morph not observed.

Asexual morph: hyalorhinocladiella-like.

Hyalorhinocladiella-like morph: conidiogenous cells arising directly from superficial hyphae, (11.5-) 12.5-27 ($28) \times 2-3 \mu \mathrm{m}$. Conidia hyaline, smooth, elliptical, aseptate, (4.5-) 5.5-7 (-8.5) × 2.5-3.5 (-4) $\mu \mathrm{m}$.

Cultures: Colonies on $2 \%$ MEA at $25^{\circ} \mathrm{C}$ reaching $61 \mathrm{~mm}$ diam. in $5 \mathrm{~d}$, initially hyaline, the colonies edge thins radially, then from the centre of the colonies to the
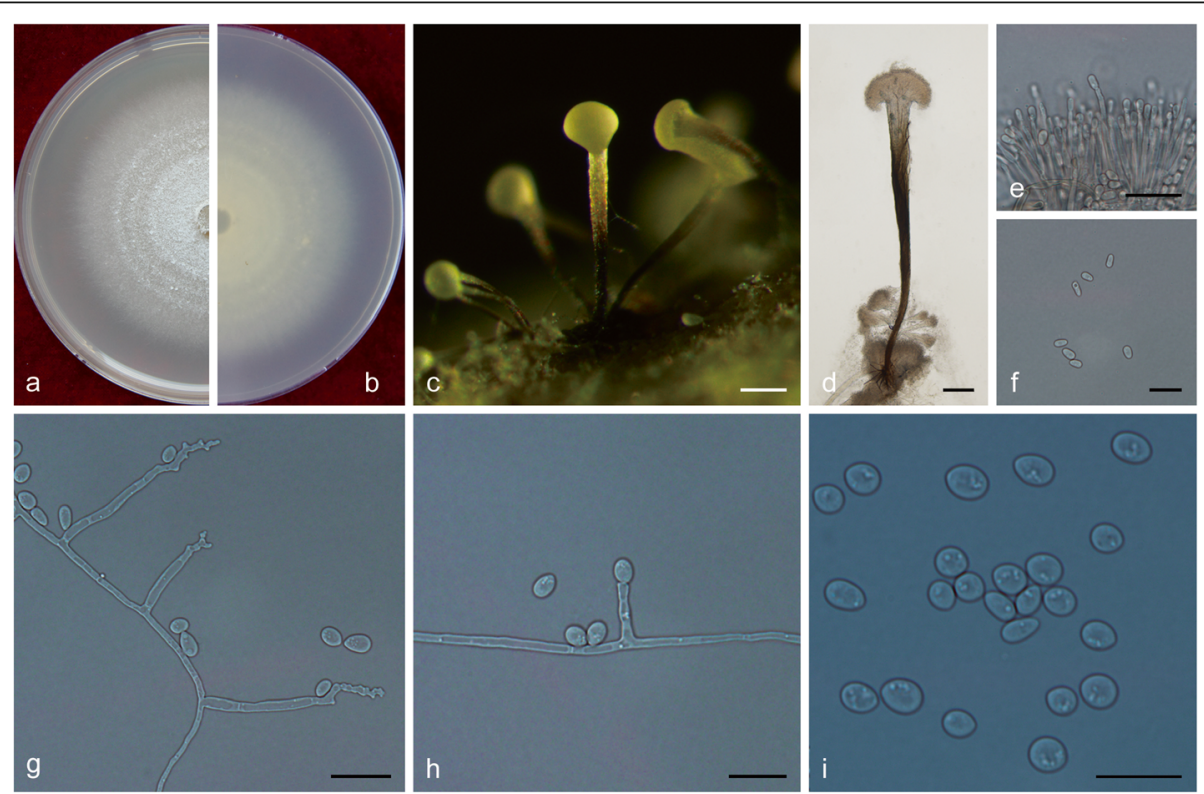

Fig. 19 Morphological characteristics of Ophiostoma xinganense sp. nov. (CFCC 52679, Taxon 11). a-b. Ten-day-old culture on 2\% MEA; c-d. Pesotum-like asexual morph; e-f. Conidiogenous cells of pesotum-like asexual morph and conidia; g. Sporothrix-like asexual morph: conidiogenous cells and conidia. $\mathbf{h}-\mathbf{i}$. Hyalorhinocladiella-like asexual morph: conidiogenous cells and conidia. Scale bars: c $=100 \mu \mathrm{m}$; $\mathrm{d}=50 \mu \mathrm{m} ; \mathrm{e}-\mathrm{i}=10 \mu \mathrm{m}$ 
periphery it becomes brownish grey and develops superficial mycelium on the agar. Optimal temperature for growth is $30^{\circ} \mathrm{C}$; no growth observed at $5^{\circ} \mathrm{C}$ or $40^{\circ} \mathrm{C}$.

Ecology: Isolated from Ips subelongatus infesting dying Larix gmelinii and L. olgensis.

Habitat: L. gmelinii or L. olgensis pure plantation.

Distribution: Currently known from the Inner Mongolia Autonomous Region and Heilongjiang province, China.

Notes: Ophiostoma subelongati forms a distinct clade within the O. clavatum complex (Linnakoski et al. 2016), in which it is closely related to O. hongxingense, O. peniculi, O. macroclavatum, O. pseudocatenulatum, and $O$. brunneolum (Fig. 6). These species share a similar hyalorhinocladiella-like state. Ophiostoma peniculi, O. macroclavatum, and O. pseudocatenulatum can be distinguished from $O$. subelongati and $O$. hongxingense by the presence of synnemata, which is absent from the latter two. The optimal growth temperature of $O$. peniculi, $O$. subelongati, and $O$. hongxingense is $30^{\circ} \mathrm{C}$, while that of $O$. macroclavatum and O. brunneolum is $25^{\circ} \mathrm{C}$. For $O$. subelongati and $O$. hongxingense, no growth observed at $5^{\circ} \mathrm{C}$ and $40^{\circ} \mathrm{C}$, but $O$. pseudocatenulatum can still grow at $5^{\circ} \mathrm{C}$. In terms of colonies characteristics, $O$. peniculi, $O$. subelongati, and $O$. hongxingense grow faster than the above three species on $2 \%$ MEA at $25^{\circ} \mathrm{C}$.

Additional specimens examined: China: Heilongjiang province, Hongxing, from Ips subelongatus infesting Larix gmelinii, July 2017, Q. Lu (culture CXY 2020 = CFCC 52694; CXY 1921; CXY 1922); Jiamusi, from Ips subelongatus infesting Larix olgensis, Aug. 2011, Q. Lu (culture CXY 1923).

Ophiostoma xinganense Z. Wang \& Q. Lu, sp. nov. MycoBank MB 830617.

(Fig. 19)

Etymology: The epithet xinganense (Latin) refers to the Xing'an mountains from where this taxon was first isolated.

Diagnosis: Ophiostoma xinganense is closely related to O. rufum. Ophiostoma xinganense develops three synanamorphs, pesotum-like, sporothrix-like and hyalorhinocladiella-like asexual states, but $O$. rufum has pesotum-like and sporothrix-like states and lacks hyalorhinocladiella-like state (Jankowiak et al. 2019). Both sporothrix-like and pesotum-like asexual states have been observed in both species, but their conidia are different in shape and size. Conidia of sporothrix-like asexual state is ovate to oblong shape with 4-5.5 (-7) $\times(2-)$ 2.5-4 (-4.5) $\mu \mathrm{m}$ in $O$. xinganense vs. clavate or fusiform (primary conidia) with (7.2-) 8.9-12.4 (- 15.2) × (2-) 2.5-3.1 (-3.4) $\mu \mathrm{m}$ in $O$. rufum, showing the former much smaller and rounder compared to the latter. Conidia of pesotum-like asexual state is ovate to oblong shape with $3.5-4.5(-5) \times 2-2.5 \mu \mathrm{m}$ in O. xinganense vs. oblong to curved shape with (2.5-) 3.3$4.5(-6.2) \times(1.2-) 1.4-1.7(-2.2) \mu \mathrm{m}$ in $O$. rufum, showing the former wider and rounder than the latter.

Type: China: Inner Mongolia Autonomous Region, Genhe, from Ips subelongatus infesting Larix gmelinii, Sept. 2017, Q. Lu (CXY 2005 - holotype, CFCC 52679 ex-type culture).

Description: Sexual morph not observed.

Asexual morphs: pesotum-like, sporothrix-like and hyalorhinocladiella-like.

Pesotum-like morph: synnemata solitary or in groups, base black, (16.5-) 29.5-80 (-114.5) $\mu \mathrm{m}$ wide, (446-) 483-768 (-953) $\mu \mathrm{m}$ tall including the conidiogenous apparatus. Conidiogenous cells (11-) 13-23.5 ($29.5) \times(1-) 1.5-2 \mu \mathrm{m}$. Conidia hyaline, smooth, ovate to oblong, aseptate, 3.5-4.5 $(-5) \times 2-2.5 \mu \mathrm{m}$. Sporothrixlike morph: conidiogenous cells arising directly from hyphae, $(15.5-)$ 21.5-49.5 (-79) × 1.5-2 (-2.5) $\mu \mathrm{m}$. Conidia hyaline, smooth, ovate to oblong, aseptate, 4-5.5 $(-7) \times(2-) \quad 2.5-4 \quad(-4.5) \mu \mathrm{m}$. Hyalorhinocladiella-like morph: conidiogenous cells arising directly from hyphae, (9.5-) 11-18.5 (-23) × 1.5-2 (-2.5) $\mu \mathrm{m}$. Conidia hyaline, smooth, ovate to oblong, aseptate, (4-) 4.5-5 (5.5) $\times 3-4 \mu \mathrm{m}$.

Cultures: Colonies on $2 \%$ MEA at $25^{\circ} \mathrm{C}$ reaching $75 \mathrm{~mm}$ diam. in $10 \mathrm{~d}$, initially whitish gray, the colonies edge thinning radially; hyphae mostly superficial, sparsely aerial, synnemata developing abundantly in the colonies centre. Optimal temperature for growth at $25^{\circ} \mathrm{C}$, no growth observed at $5{ }^{\circ} \mathrm{C}$ and $40^{\circ} \mathrm{C}$.

Ecology: Isolated from Ips subelongatus infesting dying Larix gmelinii and stock log.

Habitat: L. gmelinii pure plantation.

Distribution: Currently only known from the Inner Mongolia Autonomous Region, China.

Notes: Ophiostoma xinganense is closely related to $O$. rufum and O. brunneum (Hausner et al. 2003, Jankowiak et al. 2019) (Fig. 3). Ophiostoma xinganense and $O$. 
Table 2 Strains of ophiostomatoid fungi associated with Ips subelongatus in northeast China

\begin{tabular}{|c|c|c|c|c|c|c|c|}
\hline \multirow[t]{2}{*}{ Genus } & \multirow[t]{2}{*}{ Species } & \multirow[t]{2}{*}{ Distribution } & \multirow[t]{2}{*}{ Host } & \multicolumn{2}{|c|}{ Numbers of isolates } & \multirow[t]{2}{*}{ Total } & \multirow{2}{*}{$\begin{array}{l}\text { Total } \\
\text { percentage }\end{array}$} \\
\hline & & & & Beetles & Galleries & & \\
\hline \multicolumn{8}{|l|}{ Ophiostomatales } \\
\hline \multirow[t]{11}{*}{ Ophiostoma s.l. } & $\begin{array}{l}\text { O. genhense sp. nov. } \\
\text { (Taxon 1) }\end{array}$ & Inner Mongolia & Larix gmelinii & 0 & 2 & 2 & 0.4 \\
\hline & $\begin{array}{l}\text { O. hongxingense sp. nov. } \\
\text { (Taxon 2) }\end{array}$ & $\begin{array}{l}\text { Inner Mongolia } \\
\text { and Heilongjiang }\end{array}$ & L. gmelinii and L. olgensis & 71 & 17 & 88 & 17.7 \\
\hline & $\begin{array}{l}\text { O. lotiforme sp. nov. } \\
\text { (Taxon 3) }\end{array}$ & Inner Mongolia & Pinus sylvestris var. mongolica & 0 & 2 & 2 & 0.4 \\
\hline & O. minus (Taxon 4) & Inner Mongolia & $\begin{array}{l}\text { L. gmelinii } \\
\text { and P. sylvestris var. mongolica }\end{array}$ & 0 & 4 & 4 & 0.8 \\
\hline & $\begin{array}{l}\text { O. multisynnematum sp. } \\
\text { nov. (Taxon 5) }\end{array}$ & Inner Mongolia & L. gmelinii & 0 & 9 & 9 & 1.8 \\
\hline & O. olgensis (Taxon 6) & $\begin{array}{l}\text { Inner Mongolia } \\
\text { and Heilongjiang }\end{array}$ & L. gmelinii and L. olgensis & 21 & 17 & 38 & 7.7 \\
\hline & $\begin{array}{l}\text { O. peniculi sp. nov. } \\
\text { (Taxon 7) }\end{array}$ & $\begin{array}{l}\text { Inner Mongolia } \\
\text { and Heilongjiang }\end{array}$ & L. gmelinii and L. olgensis & 39 & 79 & 118 & 23.8 \\
\hline & $\begin{array}{l}\text { O. pseudobicolor sp. } \\
\text { nov. (Taxon 8) }\end{array}$ & $\begin{array}{l}\text { Inner Mongolia } \\
\text { and Heilongjiang }\end{array}$ & $\begin{array}{l}\text { L. gmelinii, L. olgensis and L. } \\
\text { principis-rupprechtii }\end{array}$ & 30 & 42 & 72 & 14.5 \\
\hline & O. rufum (Taxon 9) & Inner Mongolia & L. gmelinii & 0 & 7 & 7 & 1.4 \\
\hline & $\begin{array}{l}\text { O. subelongati sp. } \\
\text { nov. (Taxon 10) }\end{array}$ & $\begin{array}{l}\text { Inner Mongolia } \\
\text { and Heilongjiang }\end{array}$ & L. gmelinii and L. olgensis & 83 & 20 & 103 & 20.8 \\
\hline & $\begin{array}{l}\text { O. xinganense sp. } \\
\text { nov. (Taxon 11) }\end{array}$ & Inner Mongolia & L. gmelinii & 0 & 17 & 17 & 3.4 \\
\hline Ceratocystiopsis & $\begin{array}{l}\text { C. cf. pallidobrunnea } \\
\text { (Taxon 12) }\end{array}$ & Inner Mongolia & P. sylvestris var. mongolica & 0 & 2 & 2 & 0.4 \\
\hline Leptographium s.l. & L. zhangii (Taxon 13) & $\begin{array}{l}\text { Inner Mongolia } \\
\text { and Heilongjiang }\end{array}$ & L. gmelinii & 13 & 3 & 16 & 3.2 \\
\hline \multicolumn{8}{|l|}{ Microascales } \\
\hline Endoconidiophora & E. fujiensis (Taxon 14) & Heilongjiang & L. gmelinii & 9 & 9 & 18 & 3.6 \\
\hline Total & & & & 266 & 230 & 496 & 100.0 \\
\hline
\end{tabular}

rufum can be distinguished from O. brunneum by the presence of a pesotum-like asexual state, which is absent in the latter. In terms of colony characteristics, $O$. xinganense colonies are whitish gray with edge thinning radially and exhibits a clear concentric pattern of creamcolored rings, but $O$. rufum colonies were brownish orange to a rust brown with margin smooth and without concentric rings. Furthermore, at their optimal growth temperature $\left(25^{\circ} \mathrm{C}\right)$, physiologically $O$. xinganense shows a radial growth over three times faster than that reported in O. rufum under the same conditions on $2 \%$ MEA ( $7.5 \mathrm{~mm} / \mathrm{d}$ vs. $2.2 \mathrm{~mm} / \mathrm{d}$, Jankowiak et al. 2019). In addition, $O$. xinganense can grow at 30 and $35^{\circ} \mathrm{C}$, but $O$. rufum can not at both temperatures.

Additional specimens examined: China: Inner Mongolia Autonomous Region, Genhe, from Ips subelongatus infesting Larix gmelinii, Sept. 2017, Q. Lu (cultures CXY 2006 = CFCC 52680; CXY 1901; CXY 1902; CXY 1903).

\section{DISCUSSION}

In this study, 496 strains of ophiostomatoid fungi were obtained from adults and galleries of Ips subelongatus infesting Larix gmelinii, L. olgensis, L. principis-rupprechtii, and Pinus sylvestris var. mongolica in northeastern China. A combination of morphological and multi-locus phylogenetic approaches allowed identification of high diversity of ophiostomatoid fungi, encompassing 14 species belonging to four genera. They included eight previously undescribed Ophiostoma species, viz. O. genhense, O. hongxingense, O. lotiforme, O. multisynnematum, O. peniculi, O. pseudobicolor, O. subelongati, and O. xinganense. Two strains remain of uncertain status, and are hitherto referred to as Ceratocystiopsis cf. pallidobrunnea. Five known species also were recorded viz. Ophiostoma minus, O. olgensis, O. rufum, Leptographium zhangii, and Endoconidiophora fujiensis.

The dominant species were $O$. peniculi, O. subelongati, and $O$. hongxingense of the $O$. clavatum complex, and 
Ophiostoma pseudobicolor in the O. ips complex representing $23.8,20.8,17.7$, and $14.5 \%$ of the isolates, respectively (Table 2). The fact that former three dominant species were not isolated from Larix principisrupprechtii might be because L. principis-rupprechtii was less distributed in northeast China and there was only one sampling site for it. Ophiostoma pseudobicolor was the only species commonly encountered from three different larches (Table 2). Four species from O. piceae complex, O. genhense, O. multisynnematum, O. rufum, and $O$. xinganense were isolated only from L. gmelinii (Inner Mongolia) (Table 2). Ophiostoma minus was isolated from L. gmelinii and Pinus sylvestris var. mongolica (Inner Mongolia), and there were two unique species $(O$. lotiforme and $C$. cf. pallidobrunnea) isolated only from P. sylvestris var. mongolica (Inner Mongolia) (Table 2). Leptographium zhangii was previously reported to have been isolated only in Heilongjiang (L. gmelinii), but we also isolated it in Inner Mongolia (L. gmelinii). Meng et al. (2015) first determined that Endoconidiophora fujiensis extensively existed in three allopatric larch forests in northeast China, and we also isolated it from $L$. gmelinii in Heilongjiang (Table 2).

In China, seven additional species of the O. clavatum complex have been recently described (Yin et al. 2016; Chang et al. 2017, 2019). Two of them are Ophiostoma shangrilae and O. poligraphi, which have been described based on isolates found in association with three bark beetles (viz. Ips shangrila and Dendroctonus micans infesting Picea purpurea; Polygraphus poligraphus and $D$. micans infesting $P$. crassifolia) from Qinghai province. The other four are Ophiostoma jiamusiensis, $O$. songshui, $O$. ainoae, and O. brunneolum, which have been described based on strains isolated from I. typographus infesting spruces in northeastern China (Yin et al. 2016; Chang et al. 2019). Ophiostoma brevipilosi was originally described from strains isolated from Tomicus brevipilosus infesting Pinus kesiya in Yunnan province (Chang et al. 2017). Ophiostoma hongxingense, O. peniculi, and O. subelongati are currently known from larch in two northeastern provinces in this study.

Ophiostoma rufum (Jankowiak et al. 2019), and three of the new species described here belong to the $O$. piceae complex (Harrington et al. 2001), which is mainly characterized by a synnematous, pesotum-like and sporothrix-like asexual state. Jankowiak et al. (2019) described $O$. rufum with a brownish orange to a rust brown colonies and a sporothrix-like asexual state. Our strains, however, differ in having whitish gray colonies and a hyalorhinocladiella-like asexual state (Additional file 10: Fig. S9). Whether these deviating characters are caused by intraspecific variation or different culture conditions remains unclear and needs to be further studied. To date, 10 species in the $O$. piceae complex have been recorded in
China (Lu et al. 2009; Paciura et al. 2010a; Yin et al. 2016; Chang et al. 2017, 2019). Four species, O. nitidum, O. micans, O. qinghaiense, and O. typographi, have been described from China (Qinghai and Heilongjiang provinces) from spruces infested by $I$. nitidus, I. typographus, $D$. micans, and Po. poligraphus (Yin et al. 2016, Chang et al. 2019). Previously, O. piceae and O. setosum were reported to associated with Larix, Pinus, and Tsuga in Jilin and Yunnan provinces ( $\mathrm{Lu}$ et al. 2009, Paciura et al. 2010a, Chang et al. 2017). The four new species here described were all isolated from I subelongatus infesting L. gmelinii in Inner Mongolia.

Ophiostoma pseudobicolor forms part of the O. ips complex (De Beer et al. 2013, De Beer \& Wingfield 2013), in which it is related to O. bicolor, a species associated with various bark beetles in China (Chang et al. 2019), Japan (Yamaoka et al. 1997), and Europe (Upadhyay 1981, Linnakoski et al. 2010). These two species can be distinguished from each other by their genetic divergences, as evidenced by the phylogenetic analyses, but also by morphological data, such as the size of the ascocarps. Furthermore, their association with bark beetles and hosts affinities are differential too.

Ophiostoma lotiforme resided in a species complex previously reported as group A (Chang et al. 2017), together with $O$. saponiodorum, O. pallidulum, O. acarorum, and O. massoniana (Linnakoski et al. 2010, Wang et al. 2018). In our study, O. lotiforme was isolated from a single location (Inner Mongolia) from Pinus sylvestris var. mongolica.

Two known species from the O. minus complex (Gorton et al. 2004), O. olgensis and O. minus, were also recorded in our study. Ophiostoma olgensis was first described from the northeastern China, associated with I. subelongatus (Wang et al. 2016); it was again observed, and the species might be common in these northeastern China larch ecosystems. Ophiostoma minus has a wide distribution in northern hemisphere pine forests (Gorton \& Webber 2000, Lu et al. 2009, Wang et al. 2019).

In a phylogenetic perspective, the $O$. minus lineage was subdivided into two clades, viz. a North American and an Eurasian clades, which are considered as two allopatric populations, each with a differential autecology as far as their host is concerned. The North American population is associated with Dendroctonus spp., whereas the Eurasian population is associated with various pine-infesting beetles (Gorton \& Webber 2000, Lu et al. 2009). In a previous study of ophiostomatoid species associated with Tomicus species infesting pines in Yunnan, southwestern China, strains of O. minus formed a distinct, third clade, which was interpreted as a third allopatric population (Wang et al. 2019). In the current study, our strains of $O$. minus clustered together with 


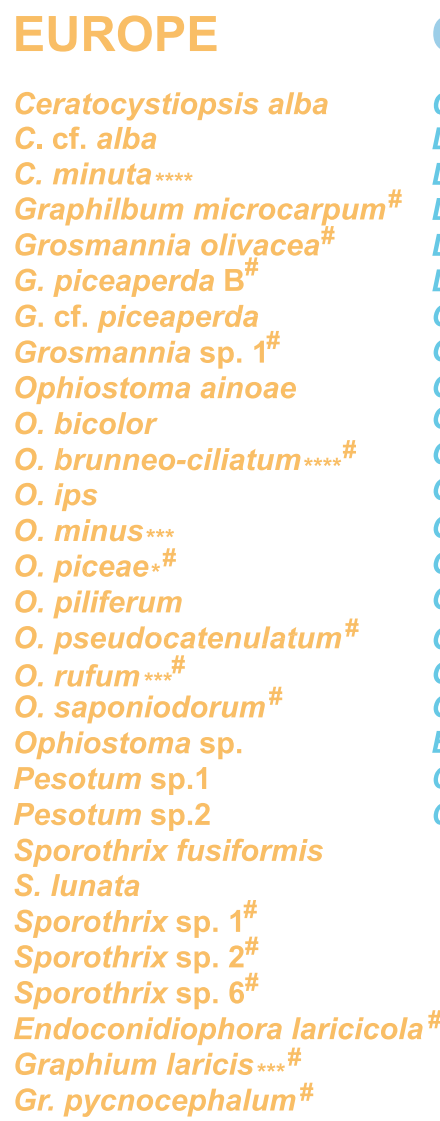

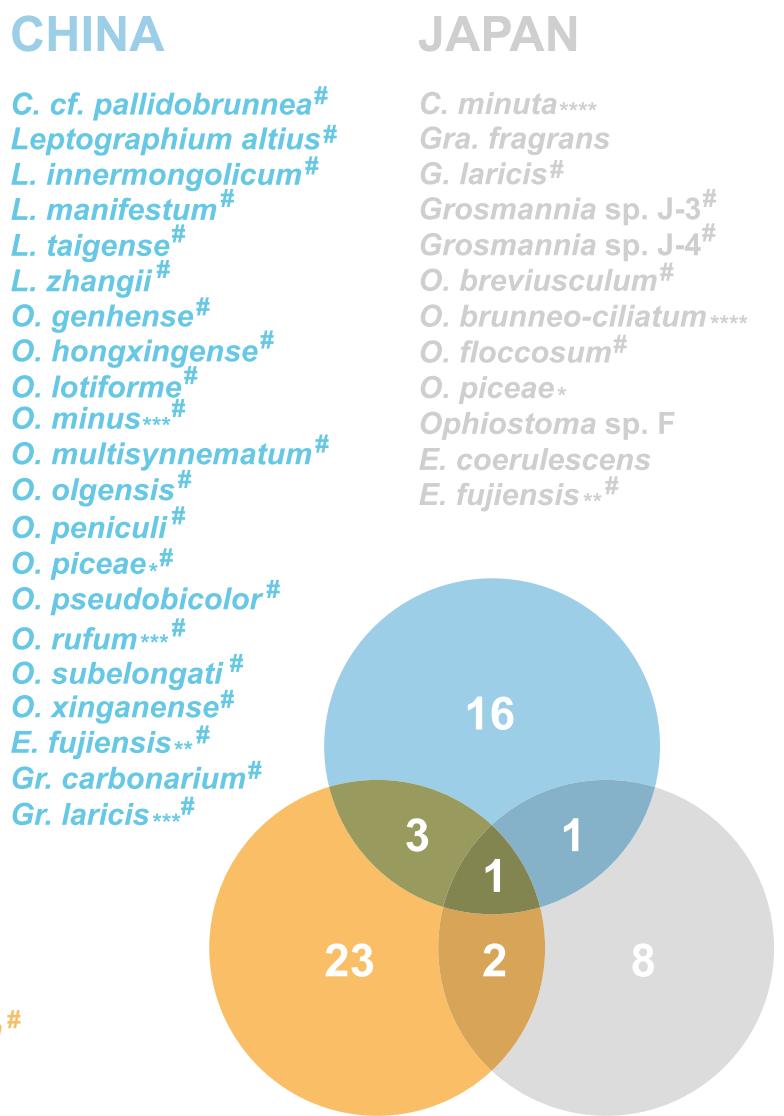

Fig. 20 Venn diagram showing overlaps of the ophiostomatoid fungal communities associated with Ips cembrae in Europe and I. subelongatus in China and Japan* species common to all three regions; ${ }^{* *}$ species common to both China and Japan; ${ }^{* *}$ species common to both China and Europe; ${ }^{* * * *}$ species common to both Europe and Japan; \# species identity confirmed by molecular data.

the Eurasian population (Figs. 4, 5) and not with the Yunnan population (Wang et al. 2019). The origin, worldwide dispersion, and insect relationships range of these populations still require further studies.

Four Leptographium species have also been isolated from Ips subelongatus in northeast China to date (Paciura et al. 2010b, Liu et al. 2016). Leptographium zhangii, which was observed also in our study, has previously been collected from other parts of northeastern China (Liu et al. 2016), confirming its widespread occurrence in the region.

Ips subelongatus and I. cembrae have been long considered as a single species with a wide distribution range. Their fungal associates were also thought to be generally identical over the presumed beetle geographic distribution range (Wood \& Bright 1992, Yamaoka et al. 1998, Stauffer et al. 2001). In particular, Endoconidiophora laricicola, a pioneer invader and the most virulent fungal associate, has also been considered as widespread fungus, following the distribution of the beetle (Yamaoka et al. 1998, Stauffer et al. 2001). However, accurate comparison of specimens of eight spined larch bark beetles from Europe and Asia showed two allopatric species, corresponding to I. cembrae and I. subelongatus (Stauffer et al. 2001). In parallel, Japanese strains of E. laricicola associated with $I$. subelongatus were shown by multigene phylogenetic inferences to also represent a distinct species, E. fujiensis (Marin et al. 2005). Another species in genus the Endoconidiophora, i.e., E. polonica, is associated with subspecies and/or distinct geographic populations of I. typographus was also shown to represent two distinct populations, that may have coevolved with the two allopatric populations of their beetle vector, I. typographus (Stauffer \& Lakatos 2000, Marin et al. 2009). Beetle and fungus speciation seemed to occur concomitantly with dispersal.

In China, Meng et al. (2015) reported that E. fujiensis is widely distributed in three larch forests in northeastern China, forming a stable association with I. subelongatus under such ecological conditions. In the present study, E. fujiensis was again collected from this area, supporting the previous observations.

The pathogenicity of the Chinese strains of E. fujiensis was tested by inoculation on mature, both native and 
introduced, larches in the field (Liu 2015). In that study, Chinese strains of $E$. fujiensis caused limited necrotic areas (approx. $5 \mathrm{~cm}$ in length over 2 months) in the three native larches, whereas it caused necrosis of more than $70 \mathrm{~cm}$ in length (over 2 months) in Japanese larch ( $L$. kaempferi) (Liu 2015), results that are very similar to those of a previous report (Yamaoka et al. 1998). The Japanese larch was introduced and has been planted over very large areas of China, from northeastern to northwestern provinces (e.g., Gansu province) down to the southern provinces (e.g., Hubei) because of its rapid growth and stress resistance (China Flora Editorial Committee of Chinese Academy of Sciences 1978, Ma \& Wang 1990, Zhu et al. 2015). Therefore, the introduction and extensive afforestation by Japanese larch in China needs careful consideration and reevaluation because of its high susceptibility to forest pathogens.

The ophiostomatoid fungi associated with I. cembrae and I. subelongatus in Palaearctic larch forests have been investigated extensively and is well documented also in Europe and Japan (Additional file 1: Table S1 and references cited therein). Based on the data available, 54 species were identified as being associated with I. cembrae and $I$. subelongatus infesting larches. Hitherto, the highest species diversity was observed in European larch forests, followed by those in China and Japan, with 29, 21, and 12 species recorded locally, respectively (Fig. 20, Additional file 1: Table S1). However, this might still reflect incomplete survey in Eastern Asia, especially China. The direct comparison among the ophiostomatoid communities is difficult. Seven species have a known distribution range extending over two or three regions. Two species are shared by China and Japan, whereas four species are shared by China and Europe, and three by Europe and Japan (Fig. 20). The 47 other species are endemic to a single region. This high level of endemism might be explained by the endemism of both the beetle vector and larch species and by the wide geographical differences. A similar conclusion was drawn from comparisons among fungal assemblages associated with $I$. typographus (Chang et al. 2019).

Ophiostoma piceae is the only species shared among Europe, Japan, and China (Fig. 20). However, in Japan, the species associated with $I$. subelongatus were identified based solely on morphological characteristics, which is poorly informative in the $O$. piceae complex. This complex has recently been greatly enriched based on multilocus DNA sequence comparisons and further phylogenetic analyses (Linnakoski et al. 2010; Yin et al. 2016; Jankowiak et al. 2017; Chang et al. 2017, 2019). It seems clear that the identity of the Japanese $O$. piceae complex strains must be reevaluated with the aid of multiple gene sequences.

Ophiostoma minus, O. rufum, and Graphium laricis occur both in Europe and northeastern China
(Pashenova et al. 1995, 2004; Kirisits et al. 2000; Stauffer et al. 2001; Jacobs et al. 2003; Kirisits 2004; Jankowiak et al. 2007; Linnakoski et al. 2010; Liu et al. 2016; Jankowiak et al. 2019). Ophiostoma minus seems to be undergoing population differentiation or a speciation process (Figs. 4, 5, Wang et al. 2019). Ceratocystiopsis minuta and O. brunneo-ciliatum were reported as present in both Europe and Japan (Aoshima 1965; Redfern et al. 1987; Redfern 1989; Yamaoka et al. 1998, 2009; Kirisits et al. 2000; Stauffer et al. 2001; Kirisits 2004; Jankowiak et al. 2007; Jankowiak et al. 2017; Yamaoka 2017); however, the reports of their existence in Japan also relied only on morphological identification, and would require molecular confirmation. This is particularly pertinent for O. brunneo-ciliatum, which is one of more frequently reported species associated with I. subelongatus in Japan (Aoshima 1965; Yamaoka et al. 1998, 2009; Yamaoka 2017).

Endoconidiophora fujiensis is the only species that is extensively associated with I. subelongatus in northeastern Asian larch forests. A concatenate phylogenetic analysis showed a genetic differentiation within this species, much higher than the intraspecific various of two sibling species, E. polonica and E. laricicola (Meng et al. 2015). These findings are consistent with the possible differentiation of the beetle vector I. subelongatus (Zhang et al. 2007, Song et al. 2011, Chen et al. 2016).

\section{CONCLUSIONS}

The results of this study indicate a high diversity of ophiostomatoid species associated with I. subelongatus infestations of larch and pine forests in northeastern China. Fourteen species were identified, of which eight Ophiostoma species were new to science. The dominant species were $O$. peniculi, O. hongxingense, and O. subelongati in the O. clavatum complex and O. pseudobicolor in the $O$. ips complex. The comparisons among ophiostomatoid communities associated with I. subelongatus in China and Japan, and with I. cembrae in Europe showed distinct assemblage patterns. The difference between Asian and European communities might be reasonable due to huge geographical distance and quite different environments, but was unexpected for the difference between northeastern Chinese and Japanese communities. However, the conclusion still need to be confirmed though molecular identification on all species compositions. As a pioneer invader, E. fujiensis caused noticeable necrosis to Japanese larch (L. kaempferi) but seemed weakly virulent to the local larches (Liu 2015). Therefore, the introduction and extensive afforestation of Japanese larch in China needs careful consideration and reevaluation because of its high susceptibility to this forest pathogen. 


\section{Supplementary information}

Supplementary information accompanies this paper at https://doi.org/10 1186/s43008-019-0025-3

Additional file 1: Table S1. Comparison of ophiostomatoid associates of Ips cembrae or I. subelongatus in Europe, China, and Japan

Additional file 2: Figure S1. ML tree of $O$. piceae complex generated from the $\beta T$ sequence data. Sequences generated from this study are printed in bold. Bold branches indicate posterior probability values $\geq 0.9$. Bootstrap values of $\mathrm{ML} / \mathrm{MP} \geq 70 \%$ are recorded at the nodes. $T=$ ex-type isolates

Additional file 3: Figure S2. $M L$ tree of $O$. piceae complex generated from the EF-1a sequence data. Sequences generated from this study are printed in bold. Bold branches indicate posterior probability values $\geq 0.9$. Bootstrap values of $\mathrm{ML} / \mathrm{MP} \geq 70 \%$ are recorded at the nodes. $\mathrm{T}=$ ex-type isolates

Additional file 4: Figure S3. ML tree of O. piceae complex generated from the CAL sequence data. Sequences generated from this study are printed in bold. Bold branches indicate posterior probability values $\geq 0.9$. Bootstrap values of $\mathrm{ML} / \mathrm{MP} \geq 70 \%$ are recorded at the nodes. $\mathrm{T}=$ ex-type isolates

Additional file 5: Figure S4. ML tree of O. clavatum complex generated from the $\beta T$ sequence data. Sequences generated from this study are printed in bold. Bold branches indicate posterior probability values $\geq 0.9$. Bootstrap values of $M L / M P \geq 70 \%$ are recorded at the nodes. $\mathrm{T}=$ ex-type isolates

Additional file 6: Figure S5. ML tree of O. clavatum complex generated from the EF-1 a sequence data. Sequences generated from this study are printed in bold. Bold branches indicate posterior probability values $\geq 0.9$. Bootstrap values of $\mathrm{ML} / \mathrm{MP} \geq 70 \%$ are recorded at the nodes. $\mathrm{T}=$ ex-type isolates

Additional file 7: Figure S6. $M L$ tree of $O$. clavatum complex generated from the CAL sequence data. Sequences generated from this study are printed in bold. Bold branches indicate posterior probability values $\geq 0.9$. Bootstrap values of $M L / M P \geq 70 \%$ are recorded at the nodes. $\mathrm{T}=$ ex-type isolates

Additional file 8: Figure S7. $M L$ tree of $L$. zhangii generated from the EF-1a sequence data. Sequences generated from this study are printed in bold. Bold branches indicate posterior probability values $\geq 0.9$. Bootstrap values of $\mathrm{ML} / \mathrm{MP} \geq 70 \%$ are recorded at the nodes. $\mathrm{T}=$ ex-type isolates

Additional file 9: Figure S8. ML tree of Endoconidiophora generated from the 605 sequence data. Sequences generated from this study are printed in bold. Bold branches indicate posterior probability values $\geq 0.9$. Bootstrap values of $\mathrm{ML} / \mathrm{MP} \geq 70 \%$ are recorded at the nodes. $\mathrm{T}=$ ex-type isolates

Additional file 10: Figure S9. Morphological characteristics of Ophiostoma rufum (CFCC 52681 Taxon 9). a-b. Ten-day-old cultures on $2 \%$ MEA; c-d. Pesotum-like asexual morph; e-f. Conidiogenous cells of pesotum-like asexual morph and conidia; g-i. Hyalorhinocladiella-like asexual morph: conidiogenous cells and conidia. Scale bars: $c=50 \mu \mathrm{m}$; $d=20 \mu m ; e-i=10 \mu m$

\section{Abbreviations}

60S: the partial 605 ribosomal protein RPL10 gene; BCCM/MUCL: the Mycothèque of the Université Catholique de Louvain, Belgium; BI: Bayesian inference; $\beta$ T: the $\beta$-tubulin gene region; $C$ : Ceratocystiopsis; $C A L$ : the calmodulin gene region; CFCC: the China Forestry Culture Collection Centre; CXY: the culture collection of the Chinese Academy of Forestry; D: Dendroctonus; E: Endoconidiophora; EF-1a: the transcription elongation factor-1a gene region; G: Grosmannia; Gr: Graphium; Gra: Graphilbum; l: Ips; ITS: Internal transcribed spacer regions 1 and 2 of the nuclear ribosomal DNA operon, including the $5.8 \mathrm{~S}$ region; L: Larix; L: Leptographium; LSU: the nuclear ribosomal large subunit region; MEA: Malt extract agar; ML: Maximum likelihood; MP: Maximum parsimony; O: Ophiostoma; P: Picea; Po: Polygraphus; s. I: Sensu lato

\section{Acknowledgements}

Q. Lu is grateful for a postdoctoral scholarship granted in the frame of the Wallonia-Brussels International Excellent Grants Program. C. Decock gratefully acknowledges the financial support received from the Belgian State (Belgian Federal Science Policy through the BCCM ${ }^{\mathrm{TM}}$ research program). We thank X.Q. Ma of the Heilongjiang Academy of Forestry for logistical planning and participation in the fieldwork; Q.L. Zhang of Inner Mongolia Agricultural University for logistical planning; Y.J. Wang of Keshiketeng Forestry Bureau of Inner Mongolia, J. Zhao of Wendao Forest Farm of Fushun County Liaoning Province for sample collection. We thank LetPub (www.letpub.com) for its linguistic assistance during the preparation of this manuscript.

\section{Adherence to national and international regulations} Not applicable.

\section{Authors' contributions}

Z. Wang conducted experiments, data analysis and manuscript writing. Y. Liu carried on the strain's DNA extraction. Samples were collected by H.M. Wang X.J. Meng and X.W. Liu. C. Decock and X.Y. Zhang designed the research and revised the manuscript. Q. Lu carried out the design of the study, sample collection, data analysis and manuscript modification.

\section{Funding}

This work was supported by the Fundamental Research Funds of CAF (CAFYBB2017ZB002) and the National Natural Science Foundation of China (Project No.: 31770682, 31070571). The funding body played only a funding role in the design of the study and collection, analysis, and interpretation of data and in writing the manuscript.

\section{Availability of data and materials}

Not applicable.

Ethics approval and consent to participate

Not applicable.

\section{Consent for publication}

Not applicable.

\section{Competing interests}

The authors declare that they have no competing interests.

\section{Author details}

'Key Laboratory of Forest Protection, National Forestry and Grassland Administration; Research Institute of Forest Ecology, Environment and Protection, Chinese Academy of Forestry, Beijing 100091, China. ${ }^{2}$ Wuqing Forestry Bureau, Tianjin 301700, China. ${ }^{3}$ Mycothèque de I'Université Catholique de Louvain (MUCL), Earth and Life Institute, Microbiology, B-1348 Louvain-la-Neuve, Belgium.

Received: 25 May 2019 Accepted: 20 December 2019

Published online: 31 January 2020

\section{References}

Aoshima K (1965) Studies on wood-staining fungi of Japan. PhD thesis, University of Tokyo, Japan

Brasier CM (1991) Ophiostoma novo-ulmi sp. nov, causative agent of current Dutch elm disease pandemics. Mycopathol 115:151-161

Chang R, Duong TA, Taerum SJ et al (2017) Ophiostomatoid fungi associated with conifer-infesting beetles and their phoretic mites in Yunnan, China. Mycokeys 2828:19-64

Chang R, Duong TA, Taerum SJ et al (2019) Ophiostomatoid fungi associated with the spruce bark beetle Ips typographus, including 11 new species from China. Persoonia 42:50-74

Chen DF, Li YJ, Zhang QH et al (2016) Population divergence of aggregation pheromone responses in Ips subelongatus in northeastern China. Insect Sci 23:728-738

China Flora Editorial Committee of Chinese Academy of Sciences (1978) Flora Reipublicae Popularis Sinicae, Tomus 7 Gymnospermae. Science Press, Beijing, pp 195-196

Chung WH, Kim JJ, Yamaoka Y et al (2006) Ophiostoma breviusculum sp. nov. (Ophiostomatales, Ascomycota) is a new species in the Ophiostoma piceae 
complex associated with bark beetles infesting larch in Japan. Mycologia 98: $801-814$

Darriba D, Taboada GL, Doallo R et al (2012) jModelTest 2: more models, new heuristics and parallel computing. Nature Methods 9:772

De Beer ZW, Duong TA, Barnes I et al (2014) Redefining Ceratocystis and allied genera. Stud Mycol 79:187-219

De Beer ZW, Duong TA, Wingfield MJ (2016) The divorce of Sporothrix and Ophiostoma: solution to a problematic relationship. Stud Mycol 83:165-191

De Beer ZW, Seifert KA, Wingfield MJ (2013) The ophiostomatoid fungi: their dual position in the Sordariomycetes. In: Seifert KA, de Beer ZW, Wingfield MJ (eds) The ophiostomatoid fungi: expanding frontiers, CBS biodiversity series, vol 12. CBS-KNAW Fungal Biodiversity Centre, Netherlands, pp 1-19

De Beer ZW, Wingfield MJ (2013) Emerging lineages in the Ophiostomatales. In: Seifert KA, de Beer ZW, Wingfield MJ (eds) The Ophiostomatoid fungi: expanding frontiers, CBA biodiversity series, vol 12. CBS-KNAW Fungal Biodiversity Centre, Netherlands, pp 21-46

De Hoog GS (1974) The genera Blastobotrys, Sporothrix, Calcarisporium and Calcarisporiella gen. Nov. Stud Mycol 7:1-84

Duong TA, De Beer ZW, Wingfield BD et al (2012) Phylogeny and taxonomy of species in the Grosmannia serpens complex. Mycologia 104:715-732

EPPO (2005) Data sheets on quarantine pests-Ips cembrae and Ips subelongatus. EPPO Bulletin 35:445-449

Glass NL, Donaldson GC (1995) Development of primer sets designed for use with the PCR to amplify conserved genes from filamentous Ascomycetes. Appl Environ Microbiol 61:1323-1330

Gorton C, Kim SH, Henricot B et al (2004) Phylogenetic analysis of the bluestain fungus Ophiostoma minus based on partial ITS rDNA and beta-tubulin gene sequences. Mycol Res 108:759-765

Gorton C, Webber JF (2000) Reevaluation of the status of the bluestain fungus and bark beetle associate Ophiostoma minus. Mycologia 92:1071-1079

Grégoire JC, Evans HF (2004) Damage and control of BAWBILT organisms an overview. In: Lieutier F, Day KR, Battisti A et al (eds) Bark and wood boring insects in living trees in Europe, a synthesis: 19-37. Kluwer Academic Publishers, Netherlands

Harrington TC, Cobb FW (1988) Leptographium root diseases on conifers. Mycologia 81:330

Harrington TC, McNew D, Steimel J et al (2001) Phylogeny and taxonomy of the Ophiostoma piceae complex and the Dutch elm disease fungi. Mycologia 93: 111-136

Hausner G, Eyjólfsdóttir GG, Reid J (2003) Three new species of Ophiostoma and notes on Cornuvesica falcata. Can J Bot 8181:40-48

Jacobs K, Bergdahl DR, Wingfield MJ et al (2004) Leptographium wingfieldii introduced into North America and found associated with exotic Tomicus piniperda and native bark beetles. Mycol Res 108:411-418

Jacobs K, Kirisits T, Wingfield MJ (2003) Taxonomic re-evaluation of three related species of Graphium, based on morphology, ecology and phylogeny. Mycologia 95:714-727

Jankowiak R, Bilański P, Strzałka B et al (2019) Four new Ophiostoma species associated with conifer-and hardwood-infesting bark and ambrosia beetles from the Czech Republic and Poland. Antonie Van Leeuwenhoek 112:15011521

Jankowiak R, Rossa R, Mista K (2007) Survey of fungal species vectored by Ips cembrae to European larch trees in Raciborskie forests (Poland). Czech Mycol 59:227-239

Jankowiak R, Strzałka B, Bilański P et al (2017) Diversity of Ophiostomatales species associated with conifer-infesting beetles in the Western Carpathians. Eur J Forest Res 136:939-956

Katoh K, Standley DM (2013) MAFFT multiple sequence alignment software version 7: improvements in performance and usability. Mol Biol Evol 30:772-780

Kirisits T (2004) Fungal associates of European bark beetles with special emphasis on the ophiostomatoid fungi. In: Lieutier F, Day KR, Battisti A et al (eds) Bark and wood boring insects in living trees in Europe, a synthesis: 185-223. Springer, Dordrecht

Kumar S, Stecher G, Tamura K (2016) MEGA7: molecular evolutionary genetics analysis version 7.0 for bigger datasets. Mol Biol Evol 33:1870-1874

Linnakoski R, De Beer ZW, Ahtiainen J et al (2010) Ophiostoma spp. associated with pine-and spruce-infesting bark beetles in Finland and Russia. Persoonia: Mol Phylogeny Evol Fungi 25:72-93

Linnakoski R, Jankowiak R, Villari C et al (2016) The Ophiostoma clavatum, species complex: a newly defined group in the Ophiostomatales, including three novel taxa. Antonie Van Leeuwenhoek 109:987-1018
Liu X (2015) Pathogenicity and species-specific detection of fungi associated with Ips subelongatus in China. Master's thesis, Chinese Academy of Forestry, China

Liu X, Lu Q, Meng X et al (2016) Identification and phylogeny of Graphium spp. (Microascales: Graphiaceae) associated with Ips subelongatus (Coleoptera: Scolytidae) in China. Sci Silvae Sinicae 52:76-86

Liu XW, Wang HM, Lu Q et al (2017) Taxonomy and pathogenicity of Leptographium, species associated with Ips subelongatus, infestations of Larix, spp. in northern China, including two new species. Mycol Prog 16:1-13

Lu M, Zhou X, Beer ZWD et al (2009) Ophiostomatoid fungi associated with the invasive pine-infesting bark beetle, Dendroctonus valens, in China. Fungal Divers 3810:133-145

Ma CG, Wang JH (1990) Developing the plantation area for Larix kaempferi in China. Forest Sci Technol Chin 4:26-28

Marin M, Preisig O, Wingfield BD et al (2005) Phenotypic and DNA sequence data comparisons reveal three discrete species in the Ceratocystis polonica species complex. Mycol Res 109:1137-1148

Marin M, Preisig O, Wingfield BD et al (2009) Single sequence repeat markers reflect diversity and geographic barriers in Eurasian populations of the conifer pathogen Ceratocystis polonica. Forest Pathol 39:249-265

Marincowitz S, Duong TA, De Beer ZW et al (2015) Cornuvesica: a little known mycophilic genus with a unique biology and unexpected new species. Fungal Biol 119:615-630

Masuya H, Kaneko S, Yamaura Y et al (2009) Ophiostomatoid fungi isolated from Japanese red pine and their relationships with bark beetles. Mycoscience 50 : 212-223

Meng XJ, Lu Q, Liu XW et al (2015) Study on the species specific associations between Ips subelongatus and ophiostomatoid fungi. Acta Ecol Sin 35:313-323

Miao ZW, Zhou WM, Huo LY et al (2001) Study on the biological characteristic of Dendroctonus valens. Shanxi Forestry Sci Technol 23:34-37

Miller MA, Pfeiffer W, Schwartz T (2010) November. Creating the CIPRES science gateway for inference of large phylogenetic trees. In: Gateway computing environments workshop (GCE). IEEE, New Orleans, pp 1-8

Musvuugwa T, De Beer ZW, Duong TA et al (2015) New species of Ophiostomatales from Scolytinae and Platypodinae beetles in the cape floristic region, including the discovery of the sexual state of Raffaelea. Antonie van Leeuwenhoek J Microb 108:933-950

Paciura D, de Beer ZW, Jacobs K et al (2010b) Eight new Leptographium species associated with tree-infesting bark beetles in China. Persoonia-Mol Phylogeny Evol Fungi 25:94-108

Paciura D, Zhou XD, Beer ZWD et al (2010a) Characterisation of synnematous bark beetle-associated fungi from China, including Graphium carbonarium sp. nov. Fungal Divers 40:75-88

Raffa KF, Gregoire JC, Lindgren BS (2015) Natural history and ecology of bark beetles. In: Vega FE, Hofstetter RW (eds) Biology and ecology of native and invasive species. Academic, Amsterdam, pp 1-40

Rayner RW. (1970) A mycological colour chart. Commonwealth Mycological Institute and British Mycological Society

Ronquist F, Huelsenbeck JP (2003) MrBayes 3: Bayesian phylogenetic inference under mixed models. Bioinformatics 1912:1572-1574

Song LW, Zhang QH, Chen YQ et al (2011) Field responses of the Asian larch bark beetle, Ips subelongatus, to potential aggregation pheromone components: disparity between two populations in northeastern China. Insect Sci. 18:311-319

Stamatakis A (2006) RAxML-VI-HPC: maximum likelihood-based phylogenetic analyses with thousands of taxa and mixed models. Bioinformatics 2221:2688-2690

Stamatakis A (2014) RaxML version 8: a tool phylogenetic analysis and postanalysis of large phylogenies. Bioinformatics 30:1312-1313

Stauffer C, Kirisits T, Nussbaumer C et al (2001) Phylogenetic relationships between the European and Asian eight spined larch beetle populations (Coleoptera, Scolytidae) inferred from DNA sequences and fungal associates. Eur J Entomol 98:99-105

Stauffer C. Lakatos F (2000) Ips typographus f. japonicus Niijima (Coleoptera, Scolytidae): a genetic analysis by allozymes and mitochondrial sequence data. In: Jandl R, Devall M, Khorchidi M, et al. (eds), Forests Soc: Role Res. XXI IUFRO world congress, august 7-12, 2000. Ed. by Kuala Lumpur, Malaysia: Pramaju Sdn. Bhd, Vol. 3, poster abstracts 397

Stielow JB, Levesque CA, Seifert KA et al (2015) One fungus, which genes? Development and assessment of universal primers for potential secondary fungal DNA barcodes. Persoonia: Mol Phylogeny Evol Fungi 35:242

Swofford DL (2003) Paup*. Phylogenetic analyses using parsimony (*and other methods) version 4.0b10. Sinauer associates, Massachusetts 
Upadhyay HP (1981) A monograph of Ceratocystis and Ceratocystiopsis. Univ, Georgia Press, Athens

Vega FE, Hofstetter RW (2014) Bark beetles: biology and ecology of native and invasive species. Elsevier Academic Press, Amsterdam and Boston

Vilgalys R, Hester M (1990) Rapid genetic identification and mapping of enzymatically amplified ribosomal DNA from several Cryptococcus species. J Bacteriol 172:4238-4246

Wang H, Lun Y, Lu Q et al (2018) Ophiostomatoid fungi associated with pines infected by Bursaphelenchus xylophilus and Monochamus alternatus in China, including three new species. MycoKeys 39:1-27

Wang H, Wang Z, Liu F et al (2019) Differential patterns of ophiostomatoid fungal communities associated with three sympatric Tomicus species infesting pines in South-Western China, with a description of four new species. MycoKeys 50:93-133

Wang HM, Lu Q, Meng XJ, et al. (2016) Ophiostoma olgensis, a new species associated with Larix spp. and Ips subelongatus in northern China. Phytotaxa 282: 282

White TJ, Bruns T, Lee SJ et al (1990) Amplification and direct sequencing of fungal ribosomal RNA genes for phylogenetics. PCR protocols: a guide to methods and applications 18:315-322

Wingfield MJ, Brockerhoff EG, Wingfield BD et al (2015) Planted forest health: the need for a global strategy. Sci 349:832-836

Wingfield MJ, Seifert KA, Webber JF (1993) Ceratocystis and Ophiostoma: taxonomy, ecology and pathogenicity. Am Phytopathological Soc:139-192

Wood SL, Bright DE. (1992) A catalog of Scolytidae and Platypodidae (Coleoptera), part 2: taxonomic index, Great Basin naturalist memoirs no. 13 Brigham Young University, US, $833 \mathrm{pp}$

Yamaoka Y (2017) Taxonomy and pathogenicity of ophiostomatoid fungi associated with bark beetles infesting conifers in Japan, with special reference to those related to subalpine conifers. Mycoscience 58:221-235

Yamaoka Y, Hizai M, Chung WH et al (2009) Constant association of ophiostomatoid fungi with the bark beetle Ips subelongatus, invading Japanese larch logs. Mycoscience 50:165-172

Yamaoka Y, Wingfield MJ, Ohsawa M et al (1998) Ophiostomatoid fung associated with Ips cembrae in Japan and their pathogenicity of Japanese larch. Mycoscience 39:367-378

Yamaoka Y, Wingfield MJ, Takahashi I et al (1997) Ophiostomatoid fungi associated with the spruce bark beetle, Ips typographus f. japonicus in Japan. Mycol Res 101:1215-1227

Yang J, Lin Q, Chen G (2007) Risk analysis of Ips subelongatus Motschulsky. J Northeast Forestry Univ 35:60-63

Yin HF, Huang FS, Li ZL (1984) Economic insect fauna of China (Fasc. 29) Coleoptera: Scolytidae. Science press, Beijing

Yin M, Wingfield MJ, Zhou X et al (2016) Multigene phylogenies and morphological characterization of five new Ophiostoma spp. associated with spruce-infesting bark beetles in China. Fungal Biol 120:454-470

Yu CM (1992) Ips subelongatus Motschulsky. In: Xiao GR (ed) Forest insect in China: 626-628. Chinese Forestry Publishing, China

Zhang QH, Schlyter F, Chen GF et al (2007) Electrophysiological and behavioral responses of Ips subelongatus to semiochemicals from its hosts, non-hosts, and conspecifics in China. J Chem Ecol 33:391-404

Zhu HY, Wang DX, Chai ZZ et al (2015) Growth law of Larix kaempferi plantations in Western Qinling. J Northwest Forestry Univ 30:1-7

\section{Publisher's Note}

Springer Nature remains neutral with regard to jurisdictional claims in published maps and institutional affiliations.

Ready to submit your research? Choose BMC and benefit from:

- fast, convenient online submission

- thorough peer review by experienced researchers in your field

- rapid publication on acceptance

- support for research data, including large and complex data types

- gold Open Access which fosters wider collaboration and increased citations

- maximum visibility for your research: over $100 \mathrm{M}$ website views per year

At BMC, research is always in progress.

Learn more biomedcentral.com/submissions 